\title{
Dopaminergic Control of Long-Term Depression/Long-Term Potentiation Threshold in Prefrontal Cortex
}

\author{
Denis Sheynikhovich, ${ }^{1}$ Satoru Otani, ${ }^{2}$ and Angelo Arleo ${ }^{1}$ \\ ${ }^{1}$ Unit of Neurobiology of Adaptive Processes, Centre National de la Recherche Scientifique (CNRS), Unité Mixte de Recherche (UMR) 7102, University \\ Pierre and Marie Curie, Paris 6, F-75005, Paris, France, and ' ${ }^{2}$ nit of Psychopathology of Central Nervous System Diseases, CNRS, UMR 7224, Institut \\ National de la Santé et de la Recherche Médicale, U952, University Pierre and Marie Curie, Paris 6, F-75005, Paris, France
}

Long-term memory in the prefrontal cortex is a necessary component of adaptive executive control and is strongly modulated by dopamine. However, the functional significance of this dopaminergic modulation remains elusive. In vitro experimental results on dopamine-dependent shaping of prefrontal long-term plasticity often appear inconsistent and, altogether, draw a complicated picture. It is also generally difficult to relate these findings to in vivo observations given strong differences between the two experimental conditions. This study presents a unified view of the functional role of dopamine in the prefrontal cortex by framing it within the BienenstockCooper-Munro theory of cortical plasticity. We investigate dopaminergic modulation of long-term plasticity through a multicompartment Hodgkin-Huxley model of a prefrontal pyramidal neuron. Long-term synaptic plasticity in the model is governed by a calcium-and dopamine-dependent learning rule, in which dopamine exerts its action via $\mathrm{D}_{1}$ and $\mathrm{D}_{2}$ dopamine receptors in a concentration-dependent manner. Our results support a novel function of dopamine in the prefrontal cortex, namely that it controls the synaptic modification threshold between long-term depression and potentiation in pyramidal neurons. The proposed theoretical framework explains a wide range of experimental results and provides a link between in vitro and in vivo studies of dopaminergic plasticity modulation. It also suggests that dopamine may constitute a new player in metaplastic and homeostatic processes in the prefrontal cortex.

\section{Introduction}

The prefrontal cortex (PFC) is a central structure mediating executive memory and behavior (Fuster, 2008). The evidence that prefrontal cortical networks are able to actively maintain neural activity patterns (Fuster, 1973; Goldman-Rakic, 1995) fueled decades of research concerning the role of this brain area in working memory and active maintenance of executive information (such as goals or rules) in these networks (Durstewitz et al., 2000b). However, an equally important aspect of the top-down executive control theory of the PFC function (Miller and Cohen, 2001) is the ability to store information in long-term memory as opposed to short-term (working) memory. Indeed, for an efficient topdown control, relevant information is likely to be stored within the PFC itself, with the ability to load it into the working memory when required (Goto and Otani, 2007; Jung et al., 2008). An involvement of the PFC specifically in the long-term storage of executive information has been the subject of multiple theories, e.g., a cognitive switch theory (Otani, 2002), a rule representation

Received Jan. 31, 2013; revised June 21, 2013; accepted July 19, 2013.

Author contributions: S.O. and A.A. designed research; D.S. performed research; D.S. analyzed data; D.S. and A.A. wrote the paper.

This work is supported by French National Research Agency Project EVO-NEURO ANR-09-EMER-005 and the University Pierre and Marie Curie-Paris.

Correspondence should be addressed to Denis Sheynikhovich, 9 quai St. Bernard, 75005 Paris, France. E-mail: denis.sheynikhovich@upmc.fr.

S. Otani's present address: General Education Center and Department of Health Sciences Ryotokuji University, Akemi 5 chome, 8-1, Urayasu, Chiba 279-8567, Japan.

DOI:10.1523/JNEUROSCI.0466-13.2013

Copyright $\odot 2013$ the authors $\quad 0270-6474 / 13 / 3313914-13 \$ 15.00 / 0$ theory (Rougier et al., 2005), and a control memory theory (Jung et al., 2008). A large body of experimental data on different levels supports the involvement of the PFC in long-term memory storage in human patients and animals (Blumenfeld and Ranganath, 2007; Jung et al., 2008).

Synaptic correlates of long-term memory, i.e., long-term potentiation (LTP) and long-term depression (LTD), have been demonstrated in the PFC in in vitro (Hirsch and Crepel, 1990; Otani et al., 2003) and in vivo (Laroche et al., 1990; Jay, 2003) preparations. A crucial property of prefrontal long-term plasticity is that it is under a strong influence of the neuromodulator dopamine (DA), delivered to the PFC via the mesocortical dopaminergic pathway (for review, see Jay, 2003; Otani et al., 2003). Despite years of experimental studies, a functional role of such modulation remains unclear.

Importantly, properties of dopaminergic modulation of plasticity in the PFC are different from those in other structures, such as the striatum and the hippocampus, in which they have been extensively studied (Reynolds and Wickens, 2002; Sajikumar and Frey, 2004).

By studying dopaminergic modulation of synaptic adaptation in a biophysical model of prefrontal neuron, we show here that available experimental evidence can be explained from a unified perspective in the context of Bienenstock-Cooper-Munro (BCM) theory of cortical plasticity (Bienenstock et al., 1982; Cooper et al., 2004), in which amplitude and direction of plasticity are determined by the synaptic modification threshold between LTD and LTP. Within this framework, we propose a novel functional role for dopaminergic modulation of prefrontal long-term plas- 
ticity, namely that it exerts a metaplastic control over the LTD/ LTP threshold in prefrontal neurons, potentially in concert with neuronal homeostatic mechanisms. We find that such modulation is consistent with a complicated pattern of in vitro results, provides a link with in vivo studies, and suggests that tonic DA influences storage of information in long-term memory in the range of theta-gamma stimulation frequencies, important for cortical computation (Sirota et al., 2008).

\section{Materials and Methods}

Our model of DA-dependent synaptic plasticity, described below, is based on three main assumptions about properties of dopaminergic modulation in the PFC. We first state these assumptions and the rationale behind them and then describe our model in detail.

Assumption 1. We assume a determining role of tonic levels of DA, as opposed to phasic DA signals, during induction of prefrontal long-term plasticity. The tonic DA level in the PFC results from irregular background firing of dopaminergic neurons in the ventral tegmental area, whereas phasic DA signals are produced by burst firing of these neurons (Grace, 1991; Floresco et al., 2003).

The phasic activity of dopaminergic neurons has been shown to code for reward in the striatum (Apicella et al., 1992; Schultz et al., 1997). Moreover, synaptic plasticity experiments supported the idea that rapid phasic elevations of DA determine the direction and amplitude of longterm plasticity in corticostriatal synapses (Reynolds and Wickens, 2002; Pawlak and Kerr, 2008). In addition, a preferential role of phasic DA signaling in the striatum is supported by rapid mechanisms of DA release and uptake that result in high-amplitude, short-term elevation of striatal DA in response to dopaminergic fiber stimulation (Garris and Wightman, 1994).

In contrast, the hypothesis of reward signaling by DA has not been supported in the PFC, primarily because of the observation that slow dynamics of the mesocortical DA system are not well suited to encode reward-related events precisely in time (Seamans and Yang, 2004). For instance, a presentation of a reward or a short stimulation of dopaminergic input neurons causes prolonged changes in neuronal activity, making the association between reward and related neuronal activity difficult (Lavin et al., 2005). Conversely, the importance of tonic DA modulation for network computation in the PFC is well documented, and a number of models of working memory in the PFC are based on such modulation (for review, see Cohen et al., 2002; Rolls et al., 2008). In line with this, long-term plasticity experiments have shown that a switch from depression to potentiation in prefrontal synapses depends on DA conditions preceding synaptic stimulation by at least $15-40$ min rather than on concurrent phasic DA increase (Matsuda et al., 2006; Kolomiets et al., 2009).

Therefore, in our model, we postulate the key role of tonic DA in determining the sign of long-term plasticity during induction. The phasic DA release, although not addressed in this study, may contribute to protein-synthesis-dependent long-term maintenance phase of plasticity, similarly to its role in the hippocampus (Huang et al., 2004; Sajikumar and Frey, 2004).

Assumption 2. We assume that DA modulates plasticity via $\mathrm{D}_{1}$ and $\mathrm{D}_{2}$ receptor types in the PFC that act in opposite directions on synaptic plasticity. More specifically, we assume that an activation of $D_{1}$ receptors favors LTP, whereas that of $\mathrm{D}_{2}$ receptors favors LTD.

Numerous studies demonstrate that $\mathrm{D}_{1}$-type (i.e., $\mathrm{D}_{1}$ and $\mathrm{D}_{5}$ ) and $\mathrm{D}_{2}$-type (i.e., $\mathrm{D}_{2}, \mathrm{D}_{3}$, and $\mathrm{D}_{4}$ ) receptors are expressed in pyramidal neurons in rodent and primate PFC (Vincent et al., 1993; Gaspar et al., 1995; Negyessy and Goldman-Rakic, 2005; Santana et al., 2009; Zhang et al., 2010) and that both of these receptor subtypes are important for normal PFC-dependent behaviors (Seamans et al., 1998; Setlow and McGaugh, 2000; Floresco and Magyar, 2006; St Onge et al., 2011). The assumption of their antagonistic modulation of downstream signaling cascades is based on the fact that $\mathrm{D}_{1}$ and $\mathrm{D}_{2}$ receptors are coupled to G-proteins stimulating $\left(\mathrm{G} \alpha_{\mathrm{s} / \mathrm{olf}}\right)$ and inhibiting $\left(\mathrm{G} \alpha_{\mathrm{i} / \mathrm{o}}\right)$ second-messenger cAMP, respectively (Missale et al., 1998; Beaulieu and Gainetdinov, 2011). The molecular cascade mediated by protein kinase A (PKA), directly stimu- lated by cAMP, is a classical pathway implicated in bidirectional synaptic plasticity (for review, see Malenka and Bear, 2004).

Specific to the PFC, the facilitatory effect on LTP can be exerted by such $D_{1}$-dependent mechanisms as stimulation of surface expression of AMPA receptors via the cAMP-PKA pathway (Sun et al., 2005), neuronal excitability increase via the protein kinase C-phospholipase C cascade (Tseng and O'Donnell, 2004; Chen et al., 2007), and potentiation of NMDA receptor (NMDAR) responses (Zheng et al., 1999; Li et al., 2009). In vivo, $\mathrm{D}_{1}$-mediated activation of the cAMP-PKA pathway has been shown to be necessary for LTP in hippocampal (Jay et al., 1998; Gurden et al., 1999) and callosal (Coppa-Hopman et al., 2009) synapses to the PFC. Some of these $\mathrm{D}_{1}$-mediated actions are mirrored by antagonistic $\mathrm{D}_{2}$-activated cellular pathways. In particular, $\mathrm{D}_{2}$ receptors decrease excitability, downregulate AMPA trafficking, and suppress NMDAR activity (Zheng et al., 1999; Wang et al., 2003; Tseng and O'Donnell, 2004; Sun et al., 2005). In addition, $D_{2}$ receptors modulate redistribution of NMDARs away from the synapse and inhibit CaMKII, preventing LTP (Xu et al., 2009).

Although this study focuses on the antagonistic effects of $\mathrm{D}_{1^{-}}$and $\mathrm{D}_{2}$-type receptors, cooperative effects of these two receptor classes have also been reported. For example, coactivation of $D_{1} / D_{2}$ receptors leads to an increase in intracellular calcium levels in cell cultures (Lee et al., 2004) and to the activation of the mitogen-activated/extracellular-regulated kinases (MAPK/ERK; Thomas and Huganir, 2004). These data can be taken into account by suggesting that a certain level of coactivation of the two receptor types is required for any plasticity to take place, whereas above this critical level relative receptor activities determine the antagonistic effects described above. For example, the data concerning cooperative increase of calcium levels by the two receptor types are consistent with the fact that calcium elevation is required for both LTD and LTP (Otani et al., 1998). Similarly, coactivation of the two receptors has been implicated in the activation of MAPK/ERK that is required for both LTD and LTP in vitro (Otani et al., 1999; Kolomiets et al., 2009).

Assumption 3. We assume that low DA concentrations activate predominantly $\mathrm{D}_{1}$ receptors, whereas higher DA concentrations act preferentially via $D_{2}$ receptors. This assumption is supported by studies in the PFC showing that low DA concentrations enhance NMDA-mediated currents and inhibitory transmission via activation of $\mathrm{D}_{1}$ receptors, whereas high DA concentrations have an opposite effect, mediated by $\mathrm{D}_{2}$ receptors (Zheng et al., 1999; Seamans and Yang, 2004; TranthamDavidson et al., 2004; Li et al., 2009).

Neuron model. As a basis for our neuron model, we took the model of layer V pyramidal neuron from rat medial PFC, used previously to simulate DA influence on the delay-period activity (Durstewitz et al., 2000a). We modified this four-compartment (i.e., including soma, basal, proximal, and distal dendrites) model to include $N=100$ synapses, located in the distal dendritic compartment (Fig. 1A). Lengths and diameters of the four compartments were as described previously by Durstewitz et al. (2000a). Axial resistance $R_{\mathrm{a}}$ in all compartments was equal to $150 \Omega / \mathrm{cm}$. Membrane capacitance and membrane resistance in the soma were $C_{\mathrm{m}}=$ $1.2 \mu \mathrm{F} / \mathrm{cm}^{2}$ and $R_{\mathrm{m}}=30 \mathrm{k} \Omega / \mathrm{cm}^{2}$. In the dendrites, $C_{\mathrm{m}}$ was increased and $R_{\mathrm{m}}$ was decreased by a factor of 1.92 to account for the increase in dendritic membrane area attributable to spines (Durstewitz et al., 2000a). All compartments included the following: (1) fast and persistent sodium currents; (2) delayed-rectifier, slowly inactivating, and voltagedependent potassium currents; and (3) high-voltage-activated $\left(I_{\mathrm{HVA}}\right)$ calcium current. Calcium accumulation was modeled by a first-order differential equation:

$$
\frac{d\left[\mathrm{Ca}^{2+}\right]}{d t}=-A_{\mathrm{Ca}}\left(I_{\mathrm{Ca}}+I_{\mathrm{HVA}}\right)-\frac{\left[\mathrm{Ca}^{2+}\right]-\left[\mathrm{Ca}^{2+}\right]_{\mathrm{inf}}}{\tau_{\mathrm{Ca}}},
$$

where $A_{\mathrm{Ca}}$ is the calcium accumulation factor (measured in $\mathrm{mol} / \mathrm{C} \cdot \mathrm{cm}$ and equal to $2 \times 10^{-4}$ in the soma and to $5 \times 10^{-4}$ in the dendrites), $I_{\mathrm{Ca}}$ (in milliamperes per square centimeters) is the calcium current resulting from calcium influx via NMDARs (see below), $\left[\mathrm{Ca}^{2+}\right]_{\text {inf }}=50 \mathrm{~nm}$ is the baseline intracellular calcium concentration (Yamada et al., 1999), and $\tau_{\mathrm{Ca}}$ is the calcium accumulation time constant (set to $250 \mathrm{~ms}$ in the soma, $120 \mathrm{~ms}$ in the basal and proximal dendrites, and $80 \mathrm{~ms}$ in the distal dendrite; Durstewitz et al., 2000a). 
AMPA and NMDA synaptic currents were modeled as $I_{\text {syn }}=g_{\text {syn }}\left(v-E_{\text {syn }}\right)$, where synaptic conductances were double exponentials in the following form:

$$
g_{\text {syn }}=\bar{g}_{\text {syn }} Z\left[\exp \left(-t / \tau_{\text {off }}\right)-\exp \left(-t / \tau_{\text {on }}\right)\right],
$$

with $\bar{g}_{\text {syn }}$ being the maximal synaptic conductance, $\tau_{\text {on }}$ and $\tau_{\text {off }}$ the time constants, and $Z$ the normalization factor ensuring that the peak value of $g_{\text {syn }}$ is equal to $\bar{g}_{\text {syn }}$ (Dayan and Abbott, 2001). The following parameter values were set: for AMPA, $E_{\mathrm{AMPA}}=0 \mathrm{mV}, \bar{g}_{\mathrm{AMPA}}=0.03$ $\mu \mathrm{S}, \tau_{\text {on }}=0.2 \mathrm{~ms}, \tau_{\text {off }}=1 \mathrm{~ms}$; for NMDA, $E_{\mathrm{NMDA}}=0 \mathrm{mV}, \bar{g}_{\mathrm{NMDA}}=0.003 \mu \mathrm{S}, \tau_{\mathrm{on}}=2.3$ $\mathrm{ms}, \tau_{\text {off }}=95 \mathrm{~ms}$.

The plastic AMPA conductance in the $n$th synapse was scaled by a factor $s_{n}=s_{0}\left(1+z_{n}\right)$ that reflected long-term changes in synaptic conductance depending on the synaptic state $z_{n}$. The dynamics of $z_{n}$ depended on both the intrasynaptic calcium concentration and the extracellular DA concentration, as described in the next section.

For the nonplastic NMDA conductance, the double exponential was multiplied by a voltage-dependent gate:

$$
S(v)=1 /(1+0.33 \exp (-0.062 v)),
$$

implementing $\mathrm{Mg}^{2+}$ block (Jahr and Stevens, 1990). The calcium current via NMDARs was modeled as follows (Grunditz et al., 2008):

$$
I_{\mathrm{Ca}}=P_{\mathrm{Ca}} v L \frac{\left[\mathrm{Ca}^{2+}\right]-\left[\mathrm{Ca}^{2+}\right]_{\mathrm{o}} \exp (-v M)}{1-\exp (-v M)},
$$

where extracellular calcium concentration $\left[\mathrm{Ca}^{2+}\right]_{\mathrm{o}}=2 \mathrm{~mm}$, and the permeability of the NMDA channel to calcium $P_{\mathrm{Ca}}$ was calculated based on the evidence that $\sim 10 \%$ of the current through NMDA channels is carried by calcium (Jahr and Stevens, 1993). In the equation above, $L=z^{2} F^{2} / R T$ and $M=z F / R T$, where $z=$ 2 is the valence of calcium ions, $F=96485$ $\mathrm{C} / \mathrm{mol}$ is the Faraday constant, $R=8.314$ $\mathrm{J} \cdot \mathrm{mol}{ }^{-1} \cdot \mathrm{K}^{-1}$ is the gas constant, and $T=$ $308 \mathrm{~K}$ is the absolute temperature.

In the simulations reported in Results, 50 different neurons were generated by sampling compartment sizes, all ionic conductances and calcium accumulation factors from a uniform distribution $\pm 5 \%$ around the standard parameter values (Table 1 ; Durstewitz et al., 2000a). All simulations were performed using Python and Neuron 7.1 software (Carnevale and Hines, 2006; Hines et al., 2009).

Calcium-dependent long-term synaptic plasticity. Synaptic plasticity was modeled according to the calcium-control hypothesis (Shouval et al., 2002), stating that a large calcium influx is required for LTP, whereas moderate elevation of postsynaptic calcium is necessary for LTD (Lisman, 1985). This synaptic plasticity scheme was adopted because it explicitly implements LTD/LTP modification threshold (see below) and hence simplifies modeling of DA-dependent modification of this threshold, as described in the next section. Other synaptic plasticity models are compatible with our mechanism of DA modulation, as long as facilitation of LTP would entail inhibition of LTD (and vice versa) in these models.

On the level of a single synapse, we modeled depression and potentiation by the corresponding stable states of a variable $z_{n}$ with bistable dynamics (Lisman, 1985; Clopath et al., 2008):
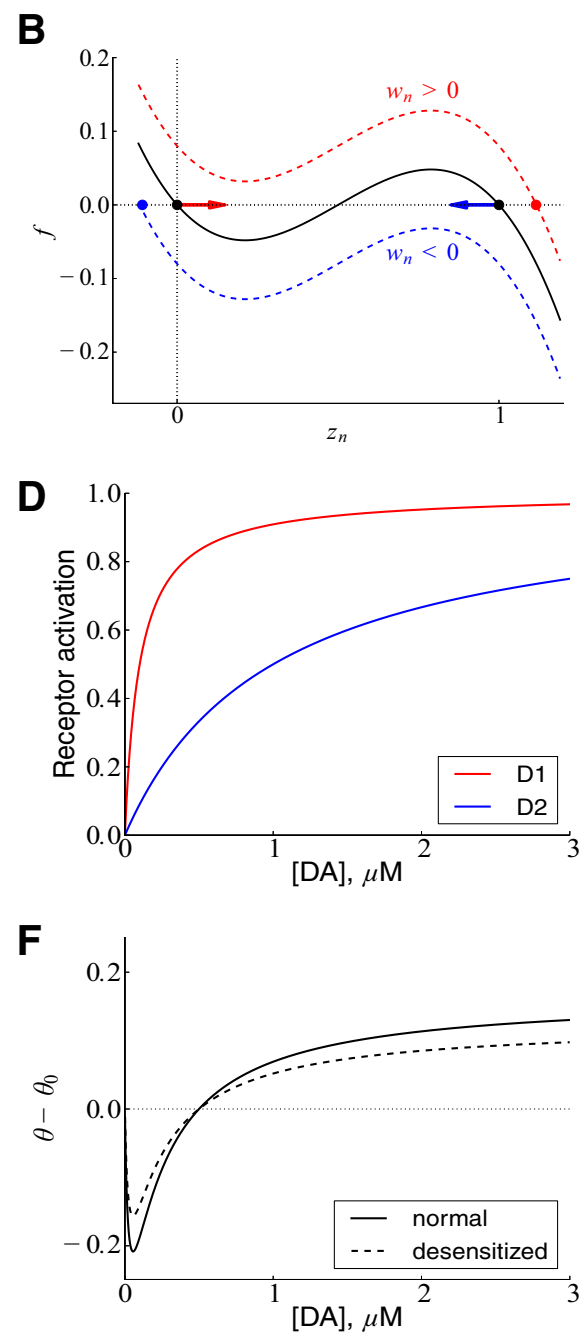

Figure 1. Model overview. $A, A$ schematic representation of the four-compartment neuron model. $\boldsymbol{B}, A$ visualization of the bistable synaptic dynamics of $z_{n}$ variable [Eq. $\left.4 ; f\left(z_{n}\right)=z_{n}\left(1-z_{n}\right)\left(z_{n}-0.5\right)\right]$. In the absence of stimulation, the synaptic state $f(z)=0$, fixed point at $z_{n}=0.5$ is unstable]. When synaptic stimulation leads to a weight increase ( $\gamma w_{n}>0$; red dashed curve) ( Function $\Omega$ (with $\theta=0.5$ ) describes the calcium-dependent weight change; dashed lines, tonic DA shifts LTD/LTP threshold $\theta$ depending on the relative activation of $D_{1}$ - or $D_{2}$-mediated cascades. $D, D_{1}$ (red curve) and $D_{2}$ (blue curve) receptor activation in the steady state, as a function of tonic $D A$ concentration. $E$, Steady-state activation of $D_{1}$-mediated $\left(e_{1}\right.$, red curve) and $D_{2}$-mediated $\left(e_{2}\right.$ blue curve) cascades by tonic DA (dotted lines correspond to the activation values for maximal receptor occupancies). $\boldsymbol{F}$, Modulation of threshold $\theta$ in $\boldsymbol{C}$ by tonic DA. In $\boldsymbol{E}$ and $\boldsymbol{F}$, the dashed lines correspond to desensitized DA-mediated enzyme activities and the resulting changes in the plasticity threshold, respectively.

$$
\tau_{z} \frac{d z_{n}}{d t}=z_{n}\left(1-z_{n}\right)\left(z_{n}-0.5\right)+\gamma w_{n}
$$

Here, $\tau_{z}$ determines the timescale of the dynamics, the first term on the right ensures the existence of the two stable states, i.e., $z_{n}=1$ for a potentiated synapse and $z_{n}=0$ for the depressed one (Fig. $1 B$ ), and the second term on the right describes calcium dependence (with strength $\gamma$ ). More specifically, in the $n$th synapse, the change in weight $w_{n}$ depends in a U-shaped manner on the intrasynaptic calcium concentration $\left[\mathrm{Ca}^{2+}\right]_{\mathrm{n}}$ (Shouval et al., 2002; Yeung et al., 2004):

$$
\frac{d w_{n}}{d t}=\eta \Omega\left(\theta,\left[\mathrm{Ca}^{2+}\right]_{\mathrm{n}}\right)-\lambda w_{n}
$$

where function $\Omega$ is shown in Figure $1 C, \theta$ denotes the DA-modulated LTD/LTP threshold (see below), $\eta$ is the learning rate (proportional to 
Table 1. Model parameters

\begin{tabular}{|c|c|c|c|}
\hline \multicolumn{4}{|l|}{ Calcium-dependent plasticity } \\
\hline Scaling factor for synaptic weight & $\gamma$ & 1 & \\
\hline Time constant of synaptic state change & $\tau_{z}$ & 100 & $S$ \\
\hline Weigh decay constant & $\lambda$ & 0.02 & \\
\hline Learning rate & $\eta$ & $1 \cdot[\mathrm{Ca}]$ & $1 /(\mathrm{ms})$ \\
\hline Initial weight & $w_{0}$ & 1 & \\
\hline \multicolumn{4}{|l|}{ Dopaminergic modulation of plasticity } \\
\hline Binding rate for $D_{1}$ receptor & $\alpha_{\mathrm{D} 1}$ & 10 & $1 /(s \cdot \mu \mathrm{m})$ \\
\hline Unbinding rate for $D_{1}$ receptor & $\beta_{\mathrm{D} 1}$ & 1 & $1 / \mathrm{s}$ \\
\hline Binding rate for $D_{2}$ receptor & $\alpha_{\mathrm{D} 2}$ & 1 & $1 /(s \cdot \mu \mathrm{m})$ \\
\hline Unbinding rate for $D_{2}$ receptor & $\beta_{\mathrm{D} 2}$ & 1 & $1 / s$ \\
\hline$D_{1}$ enzyme activation rate & $k_{1, e 1}$ & 1 & $1 / \min$ \\
\hline$D_{1}$ enzyme deactivation rate & $k_{2, e 1}$ & 0.5 & $1 / \mathrm{min}$ \\
\hline Total concentration of $D_{1}$-activated enzyme & $e_{1, \mathrm{~T}}$ & 1 & \\
\hline$D_{2}$ enzyme activation rate & $k_{1, e 2}$ & 2 & $1 / \min$ \\
\hline $\mathrm{D}_{2}$ enzyme deactivation rate & $k_{2, e 2}$ & 0.4 & $1 / \mathrm{min}$ \\
\hline Total concentration of $D_{2}$-activated enzyme & $e_{2, \mathrm{~T}}^{2,2}$ & 1 & \\
\hline Initial value of LTD/LTP threshold & $\theta_{0}^{2,1}$ & 0.5 & \\
\hline Scaling factor for threshold modulation & $\kappa$ & 1 & \\
\hline \multicolumn{4}{|l|}{ Integrate-and-fire model } \\
\hline Maximal NMDA conductance & $g_{\mathrm{T}}$ & $0.09^{a}$ & $\mathrm{~mm} / \mathrm{mV}$ \\
\hline NMDA adaptation parameter & $v_{g}$ & 10 & $\mathrm{mV}$ \\
\hline NMDA removal rate constant & $k_{-}^{9}$ & $10^{-5}$ & $1 /\left(m s \cdot m V^{2}\right)$ \\
\hline NMDA insertion rate constant & $k_{+}$ & $10^{-5}$ & $1 /\left(m s \cdot m V^{2}\right)$ \\
\hline
\end{tabular}

Only parameter values referenced in text are given. Parameters given without units are dimensionless. For the full specification of the multicompartment neuron model, see Durstewitz et al. (2000a). For the full specification of the integrate-and-fire neuron model, see Yeung et al. (2004).

${ }^{a}$ The maximal NMDA conductance in the study by Yeung et al. (2004) is divided by $20 \mathrm{~ms}$ (the time constant of calcium accumulation).

the calcium concentration), and $\lambda$ is the weight decay constant. The calcium concentration in Equation 5 is measured relative to the baseline value $\left[\mathrm{Ca}^{2+}\right]_{\text {inf }}$. The exact functional form of $\Omega$ is not crucial as long as it is zero at $\left[\mathrm{Ca}^{2+}\right]_{\mathrm{n}}=0$ and $\left[\mathrm{Ca}^{2+}\right]_{\mathrm{n}}=\theta$ and depression is followed by potentiation as the calcium concentration increases.

We assumed that, before stimulation, $30 \%$ of synapses in the model neuron were in the potentiated state $\left(z_{n}=1\right)$ and the rest in the depressed state $\left(z_{n}=0\right)$ based on experimental data from minimal stimulation experiments (O'Connor et al., 2005). Synaptic stimulation increases calcium concentration inside a synapse, leading to changes in synaptic weights $w_{n}$. Whereas a low-frequency stimulation results in a moderate elevation of the intracellular calcium concentration and a consequent weight decrease, a high-frequency stimulation resulted in a large calcium influx and a weight increase. During simulations of in vitro experiments, these changes in synaptic weights $w_{n}$ were transient and did not contribute to the long-term (i.e., tens of minutes after stimulation) change in the synaptic state, unless the stimulation at a particular frequency was sufficiently long (according to the timescale set by $\tau_{z}$ ). Such a long stimulation could induce a state switch in the bistable dynamics (Fig. $1 B, C$; Eq. 4), thereby contributing to a long-term synaptic change. The effective longterm change in total synaptic strength was calculated based on the number of synapses that switched their state as a result of stimulation:

$$
\Delta W=\frac{\langle W(t)\rangle}{\langle W(0)\rangle}
$$

where the average total synaptic strength is determined by:

$$
\langle W\rangle=N^{-1} \sum_{n=1}^{N} w_{0}\left(1+z_{n}\right) .
$$

Because, initially, $z_{n}=1$ in one-third of synapses, the maximal weight ratio after stimulation is $\Delta W_{\max }=(N+N) /(N+0.3 N)=1.53$, whereas the minimal weight ratio is $\Delta W_{\min }=N /(N+0.3)=0.77$. These values approximately correspond to the amplitudes of LTP (156 $\pm 13 \%$, induced by $300 \mathrm{~Hz}$ tetanus; Huang et al., 2004) and LTD (-23 $\pm 6.4 \%$, induced by $3 \mathrm{~Hz}$ stimulation; Bai et al., 2012) observed in rodent PFC neurons in vitro.

Note that, in this model, the resulting amplitude of long-term plasticity depends on the frequency of stimulation (via the changes in intrasynaptic calcium; Eq. 5) and its length (as determined by $\tau_{z}$; Eq. 4), taking into account the fact that, in in vitro experiments, the strength of LTP and LTD depended on the number and frequency of spike trains (Huang et al., 2004; Kolomiets et al., 2009).

We also note that, in this plasticity model, synaptic changes are determined by the intracellular calcium concentration, which depends on calcium current $I_{\mathrm{HVA}}$ and calcium influx via NMDA channels. These currents in turn depend on synaptic depolarization $v$. It is not essential in this model whether this depolarization comes from backpropagating action potentials (BPAPs; Shouval et al., 2002; Gulledge and Stuart, 2003) or from other mechanisms, such as local dendritic depolarization (Larkum et al., 2009), and hence the model is in principle compatible with both these possibilities.

Dopaminergic modulation of long-term plasticity. A crucial property of our model is the modulation of synaptic plasticity by DA, acting via $D_{1}$ and $\mathrm{D}_{2}$ receptor types. Dopaminergic influence on synaptic plasticity in our model is based on three main assumptions, stated previously. Here we describe how these assumptions are taken into account when constructing our plasticity model.

According to assumption 1, background DA level in the simulations was described by an overall tonic concentration [DA], neglecting rapid (i.e., in the timescale of seconds) changes in DA concentration resulting from phasic release (Garris and Wightman, 1994). More specifically, an exogenous bath application of DA was modeled as an elevation in DA concentration for the indicated time, with subsequent exponential washout with the time constant of $5 \mathrm{~min}$.

According to assumption 2, tonic DA levels activate dopaminergic $\mathrm{D}_{1}$ and $\mathrm{D}_{2}$ receptors in prefrontal neurons. Our model of dopaminergic plasticity modulation is based on intracellular recording studies, performed by one of the authors (S.O.) in layer $\mathrm{V}$ pyramidal neurons in rat medial PFC in vitro. In these studies, both $\mathrm{D}_{1}$ and $\mathrm{D}_{2}$ effects were consistently observed in single pyramidal neurons (Otani et al., 1998, 1999; Matsuda et al., 2006; Kolomiets et al., 2009). Therefore, our model implements both $\mathrm{D}_{1}$ and $\mathrm{D}_{2}$ receptors in the dendritic compartment of the modeled neuron (the plausibility of this assumption is discussed later; see Discussion). The response of DA receptors to tonic DA is described by a standard kinetic scheme of receptor activation (Destexhe et al., 1994):

$$
R+\mathrm{DA} \underset{\beta}{\stackrel{\alpha}{\rightleftharpoons}} R^{\star},
$$

where $R$ and $R^{\star}$ denote inactive receptors and those activated by DA, and $\alpha$ and $\beta$ are the activation and inactivation rates, respectively. If $r$ denotes the fraction of activated receptors, then its steady-state value is calculated as follows:

$$
\bar{r}=\frac{[\mathrm{DA}]}{[\mathrm{DA}]+K_{m}}
$$

where $K_{m}=\beta / \alpha$ is the effective receptor affinity, i.e., the concentration of DA that corresponds to the half-maximal activation of molecular targets activated by DA receptors (e.g., G-proteins; Fig. 1D). Assumption 3 was implemented by setting the effective affinity of $\mathrm{D}_{1}$ receptor to a higher value than that of $\mathrm{D}_{2}$ receptor (for parameter values, see Table 1 ).

DA receptors stimulate downstream molecular cascades, in particular those implicated in synaptic plasticity. We modeled these cascades by a simple kinetic scheme in which the concentration of an enzyme, activated by a particular DA receptor, increases proportionally to the activation of the receptor:

$$
E \stackrel{k_{1} r}{\rightleftharpoons} E_{2}^{*},
$$


where $E$ and $E^{*}$ are the inactive and active forms of the enzyme, respectively, $k_{1} r$ is the DA-dependent activation rate (with $r$ being the corresponding receptor activation), and $k_{2}$ is the constant deactivation rate. In the steady state, the dependence of the active enzyme concentration $e$ on the tonic DA level is given by the following:

$$
\bar{e}=\frac{e_{T}}{1+K_{d}+K_{d} \frac{K_{m}}{[\mathrm{DA}]}},
$$

where we used the steady-state value of $r$ from Equation $8, K_{d}=k_{2} / k_{1}$, and $e_{T}$ is the total enzyme concentration. In the following, we denote by $e_{1}$ and $e_{2}$ the enzymes that are activated by $\mathrm{D}_{1}$ and $\mathrm{D}_{2}$ receptors, respectively (Fig. 1E).

An antagonistic action of $\mathrm{D}_{1}$ and $\mathrm{D}_{2}$ receptors and their differential facilitation of LTP and LTD (assumption 2) was ensured in the model by (1) choosing parameters $k_{1}$ and $k_{2}$ for the two receptor types such that $\mathrm{D}_{1}$-mediated cascade was activated more strongly than the $\mathrm{D}_{2}$-mediated one (i.e., $e_{1}>e_{2}$ ) for lower DA concentrations and vice versa for large DA concentrations (Fig. 1E), and (2) modeling the influence on plasticity via a shift of the LTD/LTP modification threshold depending on the difference between $\mathrm{D}_{1}$ - and $\mathrm{D}_{2}$-mediated activities:

$$
\theta=\theta_{0}+\kappa p
$$

where

$$
\tau_{p} \frac{d p}{d t}=-p+\left(e_{2}-e_{1}\right)
$$

In Equation 11, threshold $\theta$ is from Equation 5, parameter $\theta_{0}$ determines the value of the plasticity threshold in the absence of DA modulation, and $\kappa$ determines the strength of the influence that the DA-activated enzymes exert on the threshold value. With our choice of parameters, the steadystate value of the LTD/LTP threshold $\theta$ depends on the tonic DA concentration in an inverted U-shaped manner (Fig. $1 F$ ).

Thus, in our model of DA-modulated synaptic plasticity, tonic DA levels determine a relative activation of $\mathrm{D}_{1}$ - and $\mathrm{D}_{2}$-stimulated molecular cascades. Stimulation of these cascades in turn modulates the synaptic modification threshold, thereby facilitating LTP or LTD (for a list of possible biophysical mechanisms, see Discussion). A similar modulation of synaptic modification threshold, although activity dependent rather than DA dependent, is a crucial feature of a well-known BCM theory of cortical plasticity (Bienenstock et al., 1982; Cooper et al., 2004). Therefore, our model of dopaminergic plasticity modulation puts the results of modeled experimental studies (see Results) in the context of the BCM theory. Moreover, because DA-induced changes in the modification threshold do not by themselves induce any plasticity, but rather determine the outcome of future plasticity-inducing events, they can be termed "metaplastic" (Abraham, 2008). Metaplastic modulation of BCM threshold has been demonstrated previously in the hippocampus (Abraham et al., 2001). According to our model, DA contributes to this type of synaptic plasticity in the PFC.

Dopaminergic influence on neuronal homeostasis. It has been proposed previously that metaplastic changes in LTD/LTP modification threshold may underlie another important neuronal process, synaptic homeostatsis (Abraham and Tate, 1997; Turrigiano and Nelson, 2004). Homeostatic mechanisms are thought to counteract sustained neuronal excitation or inhibition by slow adaptation of some neuronal process to prevent saturation of cellular plasticity mechanisms. A recent model by Yeung et al. (2004) (see also Shouval et al., 2002), proposed how neuronal homeostasis can be implemented by an activity-dependent adjustment of the LTD/LTP threshold on a slow timescale $(>1 \mathrm{~h})$. Because the proposed DA modulation of this threshold acts on a faster timescale (15-40 min), we were interested to see how the these two mechanisms may act in concert in an in vivo-like situation. In particular, modulation of prefrontal neurons by DA has been suggested to increase the gain function of these neurons and facilitate active maintenance of information in working memory. To check whether DA-dependent modulation of synaptic efficacy influences these processes, we implemented a combined model of DA-modulated synaptic homeostasis by making the synaptic modifi- cation threshold in the model by Yeung et al. (2004) DA dependent, as described below.

Analysis of the DA-modulated synaptic homeostasis model. In the model by Yeung et al. (2004), an excessive neuronal activity (as measured by time-averaged BPAPs) leads to a slow downregulation of NMDAR conductance and hence to an overall reduction of a stimulation-induced calcium influx. According to the synaptic plasticity rule (similar to that in Eq. 5; Fig. 1C), a decrease in calcium influx is equivalent to the rightward shift of the LTD/LTP threshold. Conversely, too low activity leads to upregulation of NMDAR, or, equivalently, a leftward shift of the modification threshold. Such an activity-dependent threshold modulation leads to homeostatic synaptic plasticity, which stabilizes neuronal firing and prevents synaptic saturation.

Here we briefly present neuronal dynamics governing synaptic plasticity in the combined model of synaptic homeostasis and dopaminergic modulation of synaptic plasticity and then present the analysis of how DA modulates neuronal gain function in this model. For a more detailed description of the calcium- and NMDA-dependent part of the model, see Yeung et al. (2004). In the model neuron with 100 synapses, the somatic voltage dynamics are modeled according to a standard integrate-and-fire scheme, in which EPSPs sum up until a fixed firing threshold is reached, at which point an output spike it emitted. The local synaptic dynamics in each of the 100 synapses are governed by four main processes: (1) describing the influence of synaptic input; (2) synaptic depolarization attributable to BPAPs; (3) synaptic plasticity; and (4) homeostatic regulation. First, an arrival of a presynaptic spike results in an AMPAmediated EPSP contributing to the somatic depolarization and the activation of NMDARs. The fraction of NMDARs occupied by glutamate is described by the variable $f_{\mathrm{NMDA}}$, whose value is close to 1 for high presynaptic firing rates and close to 0 for low rates, and that decays exponentially to 0 in the absence of stimulation.

Second, BPAPs propagating from the soma lead to an increase of synaptic voltage $v$ after each postsynaptic spike with subsequent exponential decay. Third, NMDA activation together with the synaptic depolarization cause an elevation of the intracellular calcium concentration $\left[\mathrm{Ca}^{2+}\right]$, which in turn induces changes in synaptic weights $w_{n}$ according to Equation 5. In this combined model, the value of threshold $\theta$ is modulated by DA, according to the same Equations 8-12 used in our multicompartment neuron model. Fourth, synaptic homeostasis is implemented by a slow (i.e., on a timescale of hours) activity-dependent adjustment of the number of NMDARs at the synapse via receptor insertion and removal (Yeung et al., 2004). This process is described by a first-order kinetic scheme:

$$
g_{\mathrm{NMDA}} \frac{k_{-}\left(v-v_{\text {rest }}\right)^{2}}{k_{+} v_{g}^{2}} g_{\mathrm{T}}-g_{\mathrm{NMDA}},
$$

where $g_{\mathrm{NMDA}}$ is the NMDA conductance, $v_{g}$ is a constant parameter controlling the strength of the homeostatic regulation, $v_{\text {rest }}=-65 \mathrm{mV}$ is the resting potential of the neuron, $g_{\mathrm{T}}$ is the total amount of NMDARs in the internal pool, and $k_{-}$and $k_{+}$are rate proportionality constants. According to Equation 13, the adjustment of total NMDAR conductance is controlled by synaptic depolarization $v-v_{\text {rest }}$ (attributable to output spiking and BPAPs) relative to the parameter $v_{g}=10 \mathrm{mV}$.

In simulations, the model neuron was stimulated by uncorrelated Poisson spike trains with constant rates, arriving at each of the 100 excitatory synapses. To gain an insight into model dynamics in these conditions, we considered steady-state values of the four synaptic variables $\bar{f}_{\mathrm{NMDA}}, \bar{v},\left[\overline{\mathrm{Ca}^{2+}}\right]$, and $\bar{g}_{\mathrm{NMDA}}$ (a bar over a variable denotes that it is a steady-state value; the synaptic index is omitted because all synapses are statistically identical under the assumption of constant Poisson input). In the steady state, synaptic depolarization $\bar{v}$ and NMDA activation $\bar{f}_{\mathrm{NMDA}}$ are approximately constant, and the intracellular calcium concentration is equal to the following (Castellani et al., 2001; Yeung et al., 2004):

$$
\left[\overline{\mathrm{Ca}^{2+}}\right]=\bar{g}_{\mathrm{NMDA}} \bar{f}_{\mathrm{NMDA}} H(\bar{v}) \text {, }
$$

where $H(v)=S(v)\left(v-v_{\mathrm{Ca}}\right)$ represents the voltage dependence of the calcium current through NMDARs, with reversal potential for calcium 

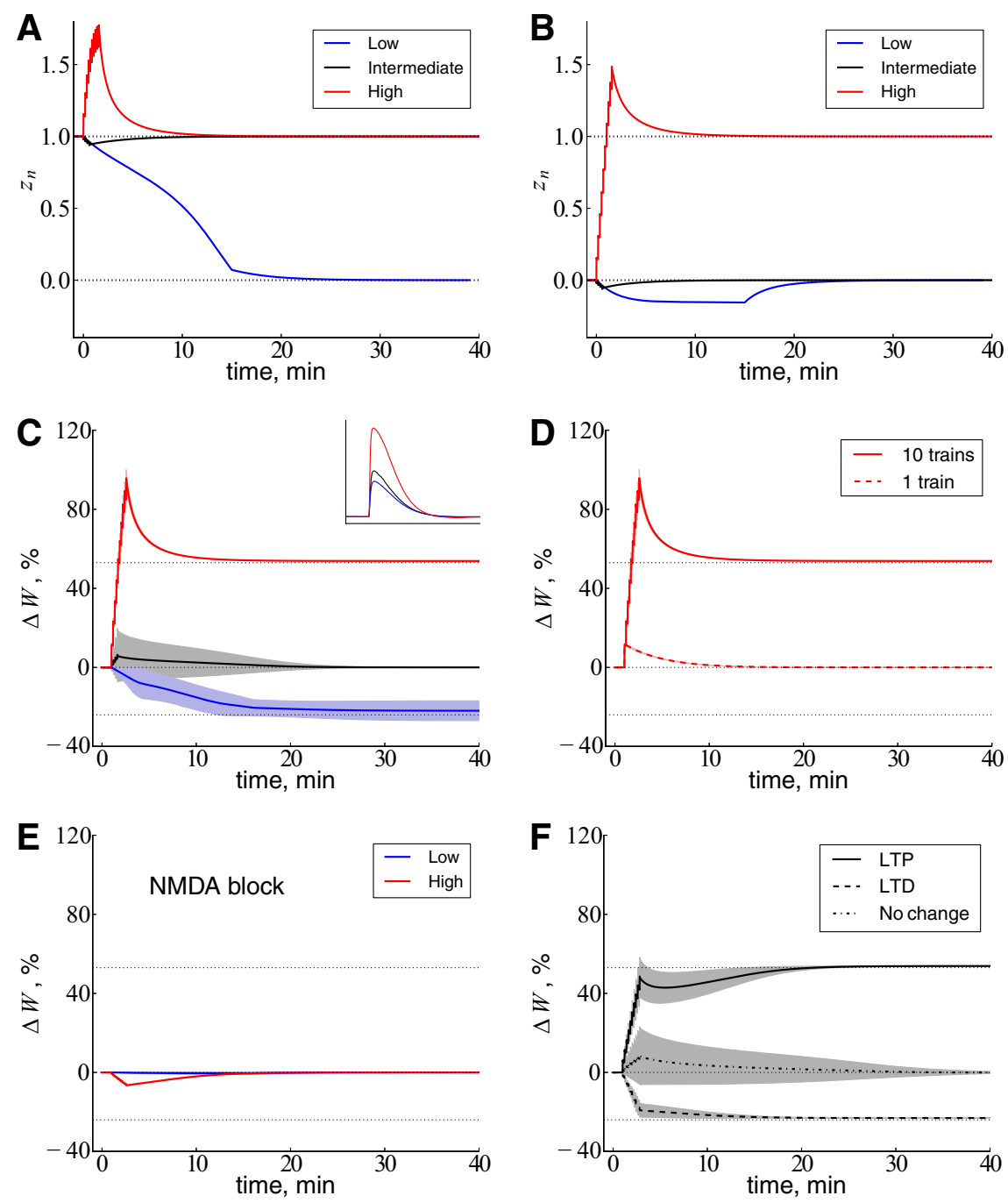

Figure 2. Synaptic plasticity in the absence of DA. $\boldsymbol{A}, \boldsymbol{B}$, Evolution of $z_{n}$ in synapses that were persistently potentiated $(\boldsymbol{A})$ or persistently depressed $(\boldsymbol{B})$ before stimulation. Blue, black, and red colors correspond to low, intermediate, and high stimulation frequencies, respectively. Stimulation is applied at $t=0$. C, An average change in total synaptic strength $\Delta W(E$ (E. 6) as a function of time, during the same stimulation as in $\boldsymbol{A}$ and $\boldsymbol{B}$. Inset, EPSPs at the soma induced by a single stimulation pulse $40 \mathrm{~min}$ after stimulation. $\boldsymbol{D}$, A short stimulation (1 train at $300 \mathrm{~Hz}$ ) is not sufficient to induce LTP (dashed red curve). The solid red curve, same as in $\boldsymbol{C}$, is plotted for comparison. $\boldsymbol{E}$, LTD and LTP are blocked when NMDA conductances are set to 0 in the model. $\boldsymbol{F}$, A longer stimulation at the intermediate frequency ( 10 trains at $50 \mathrm{~Hz}$ ) induces either LTP (solid curve), LTD (dashed curve), or no change (dot-dashed curve), depending on small changes in neuronal parameters. In $\mathbf{C} \boldsymbol{F}$, shaded areas mark corresponding \pm SE value (although not noticeable in $\boldsymbol{D}$ and $\boldsymbol{E}$ ).

$v_{\mathrm{Ca}}=130 \mathrm{mV}$ and magnesium block term $S(v)$ as in Equation 2 . The steady-state value for the NMDA conductance (i.e., the nullcline for $\bar{g}_{\mathrm{NMDA}}$ corresponding to $d g_{\mathrm{NMDA}} / d t=0$ ), is given by the following:

$$
\bar{g}_{\mathrm{NMDA}}=\frac{g_{T}}{1+k_{-}\left(\bar{v}-v_{\mathrm{rest}}\right)^{2} / k_{+} v_{g}^{2}}
$$

Finally, at the steady state of synaptic weight, $d w / d t=0$ and $\Omega(\theta$, $\left.\left[\mathrm{Ca}^{2+}\right]\right)=0$ when $\left[\mathrm{Ca}^{2+}\right]=\theta$ (see Eq. 5). Therefore, together with Equation 14, we get the following:

$$
\bar{g}_{\mathrm{NMDA}}=\frac{\theta}{\bar{f}_{\mathrm{NMDA}} H(\bar{v})} .
$$

The steady-state solution for the synaptic dynamics corresponds to the intersection point between two curves described by Equations 15 and 16 .

\section{Results}

The variability in the sign of long-term plasticity follows from proximity of induced calcium levels to LTD/LTP threshold

We first studied long-term plasticity in the biophysically realistic neuron model in the in vitro-like regime. Regular spike trains at different frequencies (from 3 to $300 \mathrm{~Hz}$ ) were delivered to the distal synapses, simulating experimental conditions of Hirsch and Crepel (1990), Otani et al. (1998), and Huang et al. (2004), in which tetanic stimulation was applied to layer I-II synapses of layer $\mathrm{V}$ pyramidal neurons in the PFC.

Depending on the stimulation frequency, single synapses in the model switched to either potentiated or depressed state, leading to an overall change in synaptic strength. In particular, if a synapse had been in the potentiated state before stimulation, then a sufficiently long low-frequency stimulation (15 min at $3 \mathrm{~Hz}$; Huang et al., 2004; Bai et al., 2012) led to a switch of the synaptic state to the depressed state (Fig. $2 A$, blue curve). In contrast, a high-frequency stimulation (10 trains at $300 \mathrm{~Hz}, 100$ spikes per train; Huang et al., 2004) did not change the synaptic state, because the synapse was already in the potentiated state (Fig. $2 A$, red curve). The picture is reversed for the depressed synapse (Fig. 2B): the highfrequency stimulation led to the switch of the synaptic state to potentiation, whereas the low-frequency stimulation had no effect. A stimulation at an intermediate frequency (i.e., four trains at 50 $\mathrm{Hz}$; Otani et al., 1998) resulted in calcium levels near LTD/LTP threshold and was too weak to induce any synaptic state switches in these conditions (Fig. $2 A, B$, black curves). The state switches are caused in the model by the weight changes, which are in turn controlled by the calcium-dependent learning rule (Eqs. 4, 5).

On the level of the whole neuron, a switch in synaptic state led to changes in the response of the postsynaptic neuron to a stimulation (Fig. 2C). More specifically, the high-frequency stimulation switched many synapses from the depressed to the potentiated state, resulting in LTP (Fig. 2C, red curve). However, stimulation at this frequency had to be sufficiently long to induce long-term changes, because one train at the same high frequency did not induced LTP (Fig. 2D; Huang et al., 2004). Conversely, the low-frequency stimulation led to LTD, because many synapses that were in the potentiated state before stimulation switched to the depressed state as a result of stimulation (Fig. 2C, blue curve). Similarly to experimentally observed LTD and LTP (Huang et al., 2004; Bai et al., 2012), these forms of plasticity required the activation of NMDARs, because blocking these receptors in the model abolished plasticity (Fig. 2E). The 

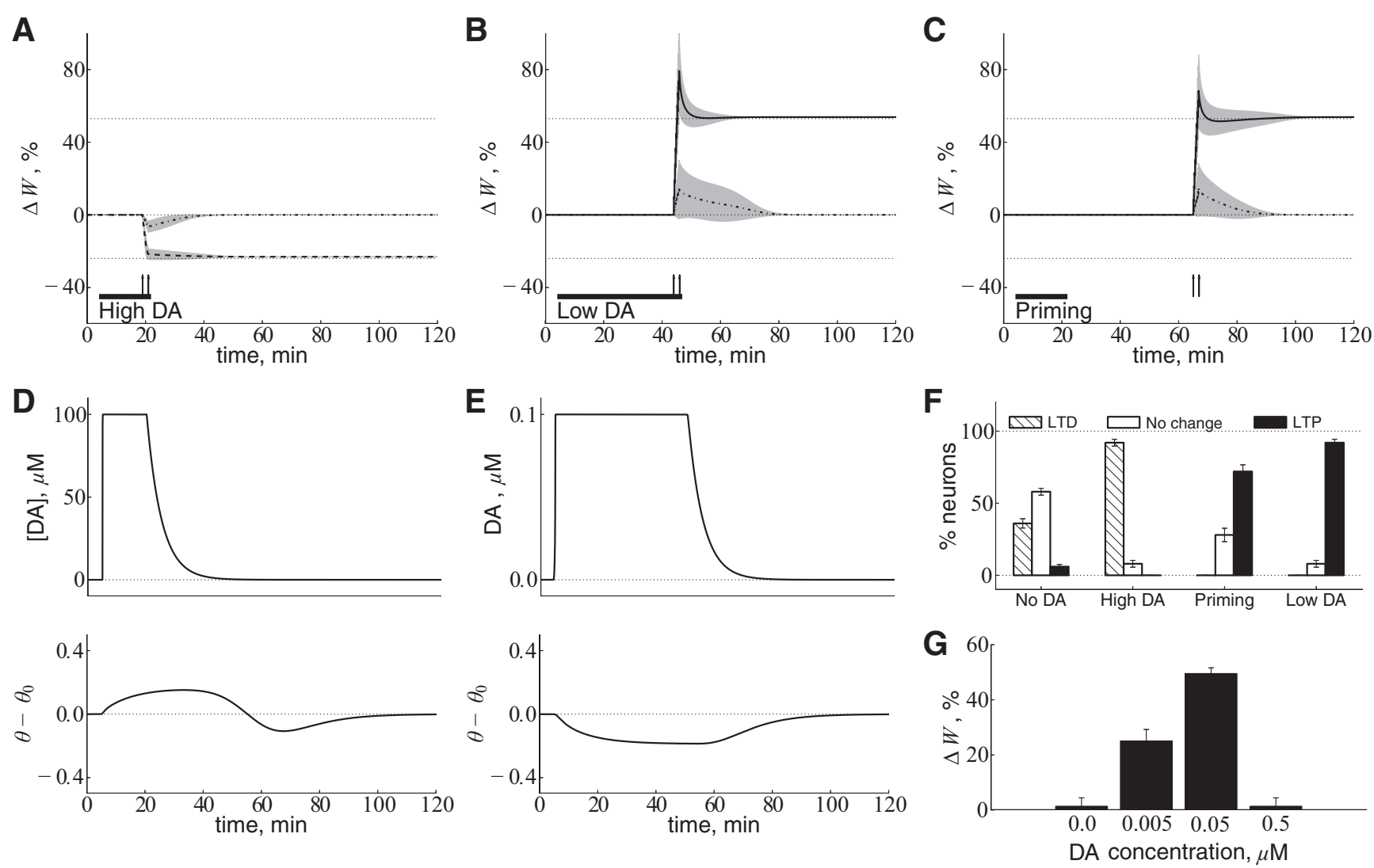

Figure 3. Modulation of synaptic plasticity by DA. $\boldsymbol{A}-\boldsymbol{C}$, The average \pm SE weight change as a function of time. $\boldsymbol{A}, \mathrm{A} 15 \mathrm{~min}$ application of a high DA concentration (100 $\mu \mathrm{m}$ ) Combined with 50 $\mathrm{Hz}$ stimulation shuts down LTP and facilitates LTD (compare with Fig. 2F). B, In contrast, a long-term application of low DA (40 min, $0.1 \mu \mathrm{M}$ ), combined with the same stimulation, shuts down LTD and facilitates LTP. C, Priming by DA (15 min at $100 \mu \mathrm{m}$ ) 40 min before stimulation converts LTD (see $\boldsymbol{A}$ ) to LTP. D, E, DA concentration (top) and the corresponding change in the plasticity threshold $\theta$ (bottom) as a function of time for the short-term $(\boldsymbol{D})$ and long-term $(\boldsymbol{E})$ application of DA (note the difference in scale). The priming effect in $\boldsymbol{C}$ is attributable to the negative shift of the LTD/LTP threshold at low DA concentration during washout. $\boldsymbol{F}$, Bars show the percentage \pm SE of neurons that underwent LTD (striped bars), no change (white bars), and LTP (black bars) in four experimental conditions: "No DA" (Fig. 2F), "High DA" (as shown in A), "Priming" (as shown in C), and "Low DA" (as shown in B). G, The average \pm SE weight change 40 min after stimulation as a function of applied low DA concentration. Increasing DA concentration led to an inverted U-shaped dependence of the LTP amplitude. Horizontal bars and vertical arrows in $\boldsymbol{A}-\boldsymbol{C}$ denote the DA application times and stimulation period, respectively.

above results were not sensitive to precise values of chosen neuronal parameters (Fig. 2C-F, shaded areas show the SEM weight change, corresponding to a uniform distribution of compartment sizes and ionic conductances $\pm 5 \%$ around standard parameter values; for details, see Materials and Methods).

Experimental data on long-term plasticity in the PFC suggest that, in contrast to the low- and high-frequency stimulation protocols, invariably resulting in LTD and LTP, the sign of plasticity, induced by a stimulation at intermediate frequencies of 50-100 $\mathrm{Hz}$, is sensitive to small changes in experimental conditions (Hirsch and Crepel, 1990; Law-Tho et al., 1995; Otani et al., 1998; Kolomiets et al., 2009). We hypothesized that this variability is attributable to the proximity of the stimulation-induced calcium rise to the LTD/LTP threshold. To test this hypothesis, we increased the number of spike trains in the $50 \mathrm{~Hz}$ stimulation from 4 to 10 , and we observed that, in these conditions, LTD was induced in 36\% and LTP in $6 \%$ of the neurons, whereas in $58 \%$ of the neurons no long-term plastic changes were induced (Figs. 2F, 3F, "No DA" condition; for an experimental support of these results, see Law-Tho et al., 1995). In the model, the differences in neuronal parameters, responsible for the distinct outcomes of plasticity induction, influence the intrasynaptic calcium concentration, because the sign of plasticity is completely determined by the calcium level relative to the LTD/LTP threshold (Eq. 5).
These results indicate that, indeed, variable outcomes of plasticity experiments in the range of intermediate stimulation frequencies are attributable to the position of the synaptic modification threshold. Importantly, very high or very low stimulation frequencies, i.e., in the regimen far from the threshold, induce only one type of plasticity (i.e., either LTP or LTD) in the model, as in the experiments. In the following sections, we show that such a sensitivity to the threshold can be exploited by tonic DA to exert control over plasticity. For the sake of clarity, we use the same stimulation protocol (i.e., 10 trains at $50 \mathrm{~Hz}$ ) to study dopaminergic influence on LTP and LTD near threshold. Qualitatively similar results will be obtained for LTP induced by a higher frequency (e.g., near $100 \mathrm{~Hz}$ ) and for LTD induced by a lower frequency (e.g., near $40 \mathrm{~Hz}$ ). The exact range of frequencies, for which the effects reported here will be observed, depends on the shape of the $\Omega$ function and calcium levels resulting from different stimulation frequencies.

\section{DA modulates the sign and amplitude of plasticity by influencing LTD/LTP threshold}

Our results so far reproduced the variability of the sign of plasticity, observed in in vitro studies of plasticity induction experiments at frequencies near $50 \mathrm{~Hz}$. The same studies suggested that changes in tonic DA strongly modulate the sign and amplitude of plasticity at these frequencies. Previous experimental studies fo- 
cused on the general properties of dopaminergic modulation of synaptic plasticity in the PFC and applied high-concentration DA stimulation (Law-Tho et al., 1994, 1995; Otani et al., 2003). The principal result of these studies is the characterization of the role of DA in synaptic depression. In contrast, later studies of dopaminergic influence in more physiological, low-concentration DA conditions unexpectedly discovered that, in these conditions, DA facilitates synaptic potentiation (Matsuda et al., 2006; Kolomiets et al., 2009). In the next set of simulations, we show that our model of dopaminergic modulation of the LTD/LTP threshold is consistent with these surprising results.

\section{Facilitation of synaptic depression by DA}

To study the influence of a high DA concentration on plasticity, we simulated an application of $100 \mu \mathrm{M}$ DA for $15 \mathrm{~min}$ in the model, similar to the experimental conditions in the studies by Law-Tho et al. (1995) and Otani et al. (1998). This DA application, combined with $50 \mathrm{~Hz}$ stimulation at the end of application period, influenced plasticity in two ways (Figs. 2F, 3A). First, in those neurons that experienced LTP in the absence of DA modulation, the LTP was blocked. Second, most of the neurons that did not undergo any plastic changes in the absence of DA expressed LTD. Figure $3 F$ compares quantitatively the number of neurons that underwent LTP, LTD, and no changes in the absence of DA ("No DA" condition) with that in the presence of the high DA concentration ("High DA" condition). Whereas the number of neurons expressing LTD significantly increased, the number of neurons that experienced no change or LTP significantly decreased. The shutdown of LTP and facilitation of LTD observed in these simulations are in agreement with experimental studies and are explained by a stronger activation of the $\mathrm{D}_{2}$-dependent pathway, relative to the $\mathrm{D}_{1}$ dependent one, at high DA concentrations. A stronger relative activation of $\mathrm{D}_{2}$ receptors in the model shifts the LTD/LTP threshold toward higher calcium concentrations and therefore favors LTD (Fig. 1C,F).

\section{Facilitation of synaptic potentiation by DA}

Basal DA levels in rodent PFC in vivo are in the nanomolar range (Hernandez and Hoebel, 1990; Bassareo and Di Chiara, 1997; Xu et al., 2009) and can be modulated during working memory tasks (Phillips et al., 2004) or as a consequence of acute stress (Morrow et al., 2000; Gresch et al., 2002) on a timescale of tens of minutes. In addition, long-term or persistent changes in DA tone can be caused by abnormal brain states, e.g., in depressed or schizophrenic patients (Grace, 1991; Yang et al., 1999). Surprisingly, in experimental conditions that more closely resembled these low physiological DA concentrations, dopaminergic effects on prefrontal synaptic plasticity were opposite to those observed for high DA concentrations (Kolomiets et al., 2009). Therefore, in addition to the involvement of DA in LTD, these experiments demonstrated the role of DA for synaptic potentiation, in agreement with in vivo studies of prefrontal long-term plasticity (Jay, 2003).

In agreement with these experiments, a long-term application of a low DA concentration in our model facilitated LTP (Fig. $3 B, F)$, in contrast to LTD facilitation at high concentrations considered previously. In particular, (1) in neurons that expressed LTD in the absence of DA modulation, this type of plasticity was blocked by the long-term application of low DA, and (2) the majority of neurons that did not express any plasticity in the absence of DA underwent LTP in its presence (Fig. 2F). Moreover, the amplitude of LTP, facilitated by the low DA concentra- tion in the model, depended in an inverted U-shaped manner on the DA concentration (Fig. $3 G$ ). This result follows directly from the U-shaped dependence of the LTD/LTP threshold on DA in our model (Fig. $1 F$ ) and reproduces the experimental observations of Kolomiets et al. (2009). Therefore, in this model, the shutdown of LTP by increasing DA concentration is attributable to the increase in $\mathrm{D}_{2}$-mediated activation pathway relative to $\mathrm{D}_{1}$-mediated one (Xu et al., 2009).

These modeling results suggest that the observed dependence of the plasticity amplitude on DA concentration is attributable specifically to the differential activation of $\mathrm{D}_{1}$ - and $\mathrm{D}_{2}$-mediated pathways by different concentrations of DA. An issue that may be raised in relation to these results is a possible involvement of desensitization processes, which may differentially decrease the potency of DA receptors to activate downstream plasticityrelated cascades after a prolonged DA application (Memo et al., 1982; Bates et al., 1991). However, the desensitization data suggest that the timescale and strength of this process are similar for $D_{1}$ and $D_{2}$ receptors $\left[D_{1}\right.$ : after 30 min stimulation, cAMP accumulation decreased by $\sim 20 \%$ at $1 \mu \mathrm{M}$, which corresponds to an approximately twofold decrease in DA potency (Memo et al., 1982); $\mathrm{D}_{2}$ : DA potency in inhibiting cAMP accumulation decreased fourfold after $1 \mathrm{~h}$ (Bates et al., 1991)]. Therefore, these processes can only contribute to the modulation of the overall level of cAMP production (and hence of the cAMP-PKAdependent synaptic plasticity), but they are unlikely to be responsible for the observed inverted U-shaped dependence on the DA concentration. To illustrate this, we decreased by $25 \%$ the maximal levels of $\mathrm{D}_{1}$ - and $\mathrm{D}_{2}$-activated enzymes in the model (parameter $e_{T}$ in Eq. 10) to simulate desensitization. This resulted in a similar U-shaped modulation of LTD/LTP threshold but with a lower amplitude compared with nondesensitized condition (Fig. 1E,F).

\section{DA priming effect and metaplasticity}

In another attempt to model more physiological conditions in vitro, Matsuda et al. (2006) studied the role of DA in a "priming" experimental paradigm, in which a high DA concentration was applied for a short time period (priming phase) and the electrical stimulation was delivered $40 \mathrm{~min}$ after the end of the priming phase. In contrast to the case when the stimulation was delivered right at the end of the first DA application (and resulted in synaptic depression as discussed before), delayed stimulation resulted in a synaptic potentiation. The priming effect occurs in our model as well (Fig. 3C). This is because $40 \mathrm{~min}$ after the end of the priming phase (i.e., $10 \mathrm{~min}$ application of DA at $100 \mu \mathrm{M}$ ), DA concentration reaches the regimen of a negative threshold modulation (i.e., below $0.5 \mu \mathrm{M}$ ) during washout (Fig. 3D). Therefore, a synaptic stimulation applied during this period leads to LTP instead of LTD (Fig. 3C,F).

An alteration of later plasticity events by priming (either pharmacologically or by a previous stimulation) has been termed metaplasticity (Abraham and Tate, 1997), which can be considered as one form of homeostatic regulation of neural activity (Turrigiano, 2008). Metaplasticity occurs when a priming stimulus induces changes in intrinsic neuronal properties that do not by themselves cause plasticity (as in conventional plasticity mechanisms) but that alter the ability of synapses to exhibit LTD or LTP. Clearly, the dopaminergic modulation of plasticity threshold in our model does not by itself cause plasticity and hence is metaplastic in nature. Although the metaplastic effect of DA priming in our present model affects mostly the induction phase of plasticity, it is likely that DA also influences the persis- 
tence of LTP and LTD (e.g., via its action on mGluR receptors and cooperative $\mathrm{D}_{1} / \mathrm{D}_{2}$ signaling; Otani et al., 1999; Abraham, 2008), not taken into account in the present model.

\section{DA-dependent modulation of LTD/LTP threshold is consistent with classical theories of dopaminergic modulation in the PFC}

Within the BCM theoretical framework, one link between synaptic plasticity and neuronal behavior in in vivo-like conditions is through the implementation of homeostatic regulation of neuronal firing (Turrigiano and Nelson, 2004) by means of the sliding BCM threshold (Yeung et al., 2004; Toyoizumi et al., 2007). In particular, previous modeling work has shown that a slow, activity-dependent modification of the LTD/LTP threshold according to a BCM-like rule may stabilize neuronal firing according to the average level of synaptic input (Yeung et al., 2004). Our results so far show that a range of in vitro experimental data can be explained by a possible dopaminergic involvement in controlling the LTD/LTP threshold, suggesting an interplay between homeostatic plasticity and dopaminergic modulation. To study how dopaminergic modulation of plasticity can act in concert with the previously proposed homeostatic mechanism, we implemented DA-dependent threshold change in the synaptic homeostasis model by Yeung et al. (2004) (for details, see Materials and Methods).

In this set of simulations, the model neuron was constantly bombarded by a Poisson-like synaptic input in the range 10-60 $\mathrm{Hz}$ (i.e., at firing frequencies observed in the PFC during various behavioral tasks; Kosobud et al., 1994; Durstewitz et al., 2000a) and in the continuous presence of a low DA concentration (10 nM at baseline, increased to either $300 \mathrm{nM}$ or $1 \mu \mathrm{M}$ in different simulations). A moderate increase in DA levels shifted the LTD/LTP threshold toward lower calcium levels, leading to a slow increase in the output firing frequency (Fig. $4 A$, red curve). A larger increase in tonic levels led to a decreased firing rate (Fig. $4 A$, blue curve) and shut down the activity at even higher concentrations (data not shown). As in the previous sections, DA-induced increase in firing rate is explained by the higher activity of $\mathrm{D}_{1}$ mediated pathway relative to the $\mathrm{D}_{2}$-mediated one. Conversely, DA-induced decrease of firing depended on a relative overactivation of the $\mathrm{D}_{2}$ - over $\mathrm{D}_{1}$-mediated pathway. These results are generally consistent with $\mathrm{D}_{1}$-mediated increase in spontaneous firing at low DA concentrations and $\mathrm{D}_{2}$-mediated suppression of spontaneous firing at higher DA concentrations in vivo (for review, see Seamans and Yang, 2004). We next compared the input-output function of the model neuron (i.e., the output frequency as a function of the input frequency) at the baseline (10 nM) and during elevated tonic DA concentration (100 nM). We observed that elevated tonic DA resulted in increased offset and gain of the inputoutput function (Fig. 4B; Thurley et al., 2008).

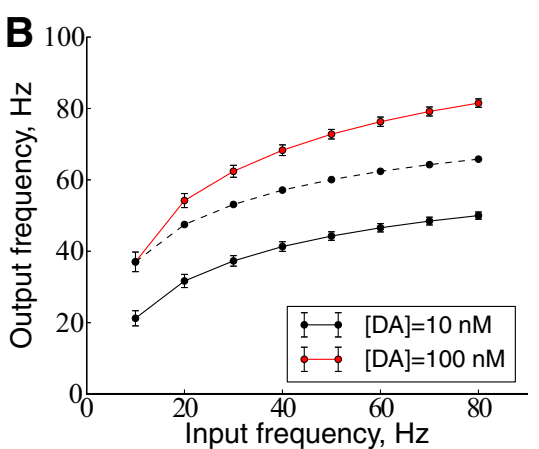

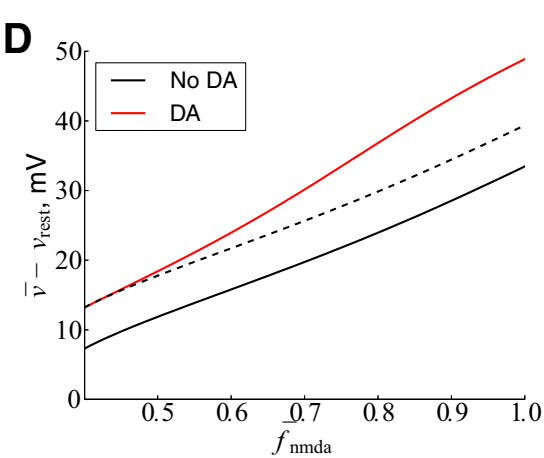

Figure 4. Gain modulation by tonic DA. $A$, The mean \pm SE output frequency of the model neuron as a function of time at baseline DA level $10 \mathrm{~nm}$ (black), moderate increase in DA ( $300 \mathrm{~nm}$, red), and strong increase in DA (1000 nm, blue). Input stimulation makectear change in gain. $C$, Phase-plane analysis of neuronal dynamics in the simplified dynamical system corresponding to postsynaptic firing rate) as a function of NMDA activation (proportional to the presynaptic spiking rate) for baseline DA condition (black curve) and elevated DA (red curve). Dashed line is a shifted copy of the solid line to make clear changes in gain.

To get an insight into this property of DA-mediated threshold modulation, we considered a simplified description of neuronal dynamics in this model (see Materials and Methods). A stable state of neuronal dynamics under the stimulation with constantfrequency Poisson spike trains is illustrated in Figure $4 C$ by an intersection of two curves corresponding to the nullclines of the dynamical system. The red curve corresponds to the nullcline of variable $g_{\mathrm{NMDA}}$ that describes the homeostatic regulation of NMDAR conductance as a function of the average membrane depolarization $\bar{v}$. The solid blue curve corresponds to the nullcline of the synaptic weight variable $w$, corresponding to presynaptic stimulation at the frequency of $F_{\text {stim }}=10 \mathrm{~Hz}$. The value of the membrane depolarization $\bar{v}$, corresponding to the intersection point between the two curves, is proportional to the steadystate value of the output spiking frequency. A higher presynaptic firing rate (e.g., $F_{\text {stim }}=50 \mathrm{~Hz}$ ) corresponds to a different $w$ nullcline (shown by the solid green curve) and leads to higher membrane depolarization and output firing rate.

In this model, a moderate increase in tonic DA concentration results in a decrease of the threshold $\theta$ and therefore shifts the $w$ nullclines down (Fig. $4 C$, dashed blue and green lines; Eq. 16). As a result, the steady-state value of the membrane depolarization increased, but, importantly, the amount of the increase was larger for higher frequencies (Fig. 4C, gray areas). This is because the $g_{\mathrm{NMDA}}$ nullcline decreases more slowly at higher membrane depolarizations. Figure $4 D$ shows the increase in neuronal gain as a result of DA modulation for a range of input frequencies 10-80 $\mathrm{Hz}$ (the difference in the shape of the input-output curves be- 
tween Fig. 4, $B$ and $D$, arises because the output frequency was replaced by membrane depolarization for theoretical analysis). We note that, in contrast to the study by Thurley et al. (2008), in which changes in neuronal gain are mediated by nonsynaptic mechanisms, in our model these changes are attributable to DAmediated metaplastic modulation of the synaptic modification threshold. These results show that, under the assumptions of the calcium control hypothesis (Shouval et al., 2002; Yeung et al., 2004), DA-induced changes in synaptic efficacy do not counteract DA-mediated gain increase postulated by theories of dopaminergic modulation of working memory (Cohen et al., 2002; Thurley et al., 2008) but may act in concert with it.

\section{Discussion}

The main contribution of the present study is the formulation of a novel hypothesis concerning a functional role of dopaminergic modulation in prefrontal long-term plasticity, namely that tonic DA controls LTD/LTP threshold in prefrontal pyramidal neurons. By relating DA effects in the PFC with the BCM theory of cortical plasticity (Cooper et al., 2004), our model explains a complicated pattern of experimental results for which a unified and coherent explanation has not been proposed. In particular, our results reproduce: (1) LTD and LTP, induced by low- and high-stimulation frequencies, respectively (Huang et al., 2004; Bai et al., 2012); (2) a variability in the sign of long-term plasticity, observed at intermediate stimulation frequencies (Hirsch and Crepel, 1990; Law-Tho et al., 1995; Otani et al., 1998, 2003; Kolomiets et al., 2009); (3) the shutdown of LTP and facilitation of LTD by a high-concentration bath of exogenously applied DA (Law-Tho et al., 1995; Otani et al., 1998; Xu et al., 2009); (4) the shutdown of LTD and facilitation of LTP by a low-concentration DA bath, including an inverted U-shaped dependence of the LTP amplitude on DA concentration (Kolomiets et al., 2009); and (5) the conversion of LTD to LTP by DA priming (Matsuda et al., 2006). We stress that, although our hypothesis of LTD/LTP threshold modulation by DA turns out to be consistent with gain modulation theories of dopaminergic modulation, it has wider functional implications. In particular, our results suggest that DA is a powerful mediator of prefrontal long-term plasticity and metaplasticity, acting on behaviorally relevant timescales and possibly in concert with other homeostatic and metaplastic neuronal processes.

In the in vitro experiments that we model (Otani et al., 1998; Matsuda et al., 2006; Kolomiets et al., 2009) and in a number of other studies (Gulledge and Jaffe, 1998; Zheng et al., 1999; Xu et al., 2009), pyramidal neurons in the PFC have shown both $\mathrm{D}_{1}$ and $\mathrm{D}_{2}$-dependent effects, probably attributable to colocalization of these receptor subtypes in pyramidal neurons. Contrary to this assumption, it has been proposed that DA receptors are expressed in different populations of prefrontal neurons (Vincent et al., 1995; Santana et al., 2009; Gee et al., 2012), suggesting a circuit-level explanation for the observed actions of DA. Several considerations argue against this explanation. First, GABAergic transmission was pharmacologically blocked in the modeled in vitro studies, ruling out cooperative action of $\mathrm{D}_{1}$ receptors in pyramidal neurons and $\mathrm{D}_{2}$ receptors in inhibitory interneurons (Xu and Yao, 2010). Second, LTD and LTP was measured by the initial rising slope of the EPSP ( $1 \mathrm{~ms}$ from the onset), which contains only a monosynaptic component (Hirsch and Crepel, 1990). Therefore, polysynaptic contributions to measured plasticity are excluded, ruling out the possibility that LTP and LTD observed in single neurons are caused by $\mathrm{D}_{1}$ and $\mathrm{D}_{2}$ receptors located in different interconnected pyramidal neurons. A third possibility, which cannot be completely excluded, is that $\mathrm{D}_{1}$ and $\mathrm{D}_{2}$ receptors, located on excitatory presynaptic terminals, modulate presynaptic neurotransmitter release (Tritsch and Sabatini, 2012). However, such a scenario would require quite specific distribution of presynaptic DA receptors (e.g., mostly $\mathrm{D}_{2}$ presynaptic receptors on terminals to $D_{1}$-expressing postsynaptic neurons and vice versa) and an antagonistic action of these receptors on the neurotransmitter release. However, the latter seems not to be the case, because both $D_{1}$ and $D_{2}$ receptors arguably depress neurotransmitter release (Tritsch and Sabatini, 2012).

Experimental studies in hippocampal neurons suggested that metaplastic facilitation of LTP may be mediated by mGluRdependent increase in neuronal excitability, by downregulating a slow afterhyperpolarization (sAHP) current and by increased trafficking of AMPA receptors. Conversely, inhibition of LTP has been related to a downregulation of NMDAR currents and modulation of $\alpha$ CaMKII (for review, see Abraham, 2008). Similar mechanisms can be involved in metaplastic modulation of LTD/ LTP threshold in the PFC. In particular, prefrontal DA is a strong bidirectional modulator of neuronal excitability (Tseng and O'Donnell, 2004; Chen et al., 2007) and of AMPA receptor trafficking (Sun et al., 2005). These mechanisms are plausible mediators of the proposed DA modulation of plasticity, because they are metaplastic, i.e., do not by themselves induce plasticity, and are antagonistically modulated by $\mathrm{D}_{1}$ and $\mathrm{D}_{2}$ receptors. In addition, $\mathrm{D}_{1}$ receptors were shown to downregulate the sAHP current in prefrontal pyramidal neurons (Thurley et al., 2008), whereas $\mathrm{D}_{2}$ receptors were reported to heterosynaptically gate LTP via NMDAR redistribution and modulation of protein phosphatase 1 activity (Xu et al., 2009), suggesting a possible contribution of these mechanisms to metaplastic DA action. Finally, as mentioned in the previous section, DA receptors may be expressed in presynaptic neuronal terminals and modulate neurotransmitter release (Tritsch and Sabatini, 2012), thereby exerting metaplastic modulation by presynaptic mechanisms, similarly to the hippocampus (Abraham, 2008).

Main predictions of the model concern set shifting and fear conditioning, the two experimental paradigms in which both $D_{1}$ and $\mathrm{D}_{2}$ receptor subtypes were implicated and that depend on long-term plasticity (for review, see Pezze and Feldon, 2004; Floresco and Magyar, 2006). In a typical set-shifting experiment, animals acquire an association between a sensory cue and reward on day 1 , whereas on day 2 another sensory cue becomes associated with reward. Importantly, the old (invalid) cue is still present on day 2, so animals have to inhibit the previously learned response (presumably stored in the long-term memory) and learn the new one. Although acquisition on day 1 does not depend on the PFC, behavioral switching on day 2 does (Floresco et al., 2006). Assuming that learning corresponds to stronger synaptic weights, inhibition of the old response would require LTD (facilitated, according to our model, when $\mathrm{D}_{2}>\mathrm{D}_{1}$ ), whereas learning of the new one would correspond to LTP (facilitated when $\mathrm{D}_{1}>$ $\mathrm{D}_{2}$ ). Our model predicts that adaptive choice of DA tone may be necessary to balance $D_{1}$ and $D_{2}$ receptor activation so as to allow LTP to occur in most active neurons (presumably those that code for the new reward contingency on day 2), while facilitating LTD in less active neurons. This novel interpretation is consistent with the data showing a differential pattern of behavioral errors induced by $\mathrm{D}_{1}$ and $\mathrm{D}_{2}$ antagonists in set shifting (Floresco et al., 2006) but stresses the role of long-term, rather than working, memory in this task. A more general testable prediction from our model is that dopaminergic modulation of LTD and LTP is required in set-shifting tasks (DeSteno and Schmauss, 2008). 
In fear conditioning experiments, a tone is associated with an electric shock during a conditioning phase on day 1. During an extinction phase on subsequent days, the tone is presented alone and the frequency of fear response (e.g., freezing) is measured. Both DA and long-term plasticity are involved in fear conditioning (Herry and Garcia, 2002; Pezze and Feldon, 2004), and moreover, PFC DA is necessary for extinction but not acquisition of fear conditioning (Morrow et al., 1999). In a way, learning of stressful content (day 1) and inhibition of response to fear/extinction learning (from day 2) is reminiscent of rule learning in set shifting, mentioned previously. If this interpretation is correct, then we predict that $\mathrm{D}_{2}$ antagonists will delay extinction (Mueller et al., 2010). Another prediction is that, in a conflict situation, e.g., when a new conditioning stimulus is paired with a shock, while an old conditioning stimulus is extinguished, the blockade of $\mathrm{D}_{1}$ and $\mathrm{D}_{2}$ receptors (or their plasticity-related molecular targets) will predominantly impair learning of a new association and extinction of the old one, respectively.

Behavioral studies considered above serve as animal models to study PFC-dependent mental disorders, such as depression, posttraumatic stress disorder, attention deficit hyperactivity disorder, and schizophrenia (Goto et al., 2010; Gamo and Arnsten, 2011). Accumulating experimental evidence from these studies led to a number of computational models of dopaminergic modulation in the PFC, focusing primarily on schizophrenia (Cohen et al., 2002; Rolls et al., 2008). The main idea coming from these studies is that prefrontal DA controls stability of neuronal representations in the PFC (Seamans and Yang, 2004). Abnormal DA modulation may thus lead to cognitive symptoms (such as distractibility and working memory deficit) and positive symptoms (e.g., bizarre thoughts, hallucinations, and delusions) that are modeled by differential modulation by DA of network attractor states (Loh et al., 2007; Rolls et al., 2008). Although these models focus on online modulation of the attractor states by DA, they are nevertheless based on long-term synaptic memory, because these attractor states are determined by the synaptic weights in the network (Rolls et al., 2008). In particular, synaptic weights determine what is loaded into working memory, and changes in these weights correspond to the information stored in the long-term memory during ongoing behavior. A general prediction of our model then is that an abnormal DA modulation of plasticity, together with an abnormal modulation of working memory, will result in the aberrant content of the long-term memory storage. This will contribute to the long-term component of positive and cognitive symptoms of schizophrenia. In particular, abnormal synaptic weights will result in noisy attractor states even when normal DA transmission is temporarily restored by drugs.

Previous modeling studies addressed DA-dependent longterm plasticity in the hippocampus, striatum, and PFC. In agreement with the importance of DA for the late phase of hippocampal LTP, DA level influenced the rate of plasticityrelated protein synthesis, but not the sign of plasticity, in the study by Clopath et al. (2008). In contrast, in striatal plasticity models, a phasic (i.e., on the timescale of few seconds) DA input modulated the direction (Thivierge et al., 2007) and amplitude (Lindskog et al., 2006; Nakano et al., 2010) of cortico-striatal plasticity. We have previously proposed that tonic DA may determine the sign of plasticity in the PFC by a simple threshold-like mechanism (Sheynikhovich et al., 2011). In the present study, we extended our previous model by showing how DA can exert bidirectional control over LTD/
LTP threshold via $\mathrm{D}_{1}$ and $\mathrm{D}_{2}$ receptors in a concentrationdependent manner.

\section{References}

Abraham WC (2008) Metaplasticity: tuning synapses and networks for plasticity. Nat Rev Neurosci 9:387. CrossRef Medline

Abraham WC, Tate WP (1997) Metaplasticity: a new vista across the field of synaptic plasticity. Prog Neurobiol 52:303-323. CrossRef Medline

Abraham WC, Mason-Parker SE, Bear MF, Webb S, Tate WP (2001) Heterosynaptic metaplasticity in the hippocampus in vivo: a BCM-like modifiable threshold for LTP. Proc Natl Acad Sci U S A 98:10924-10929. CrossRef Medline

Apicella P, Scarnati E, Ljungberg T, Schultz W (1992) Neuronal activity in monkey striatum related to the expectation of predictable environmental events. J Neurophysiol 68:945-960. Medline

Bai J, Blot K, Tzavara E, Nosten-Bertrand M, Giros B, Otani S (2012) Inhibition of dopamine transporter activity impairs synaptic depression in rat prefrontal cortex through over-stimulation of D1 receptors. Cereb Cortex. Advance online publication. Retrieved July 24, 2013. doi:10.1093/cercor/bhs376. CrossRef Medline

Bassareo V, Di Chiara G (1997) Differential influence of associative and nonassociative learning mechanisms on the responsiveness of prefrontal and accumbal dopamine transmission to food stimuli in rats fed ad libitum. J Neurosci 17:851-861. Medline

Bates MD, Senogles SE, Bunzow JR, Liggett SB, Civelli O, Caron MG (1991) Regulation of responsiveness at D2 dopamine receptors by receptor desensitization and adenylyl cyclase sensitization. Mol Pharmacol 39:55-63. Medline

Beaulieu JM, Gainetdinov RR (2011) The physiology, signaling, and pharmacology of dopamine receptors. Pharmacol Rev 63:182-217. CrossRef Medline

Bienenstock EL, Cooper LN, Munro PW (1982) Theory for the development of neuron selectivity: orientation specificity and binocular interaction in visual cortex. J Neurosci 2:32-48. Medline

Blumenfeld RS, Ranganath C (2007) Prefrontal cortex and long-term memory encoding: an integrative review of findings from neuropsychology and neuroimaging. Neuroscientist 13:280-291. CrossRef Medline

Carnevale NT, Hines ML (2006) The NEURON book. Cambridge, MA: Cambridge UP.

Castellani GC, Quinlan EM, Cooper LN, Shouval HZ (2001) A biophysical model of bidirectional synaptic plasticity: dependence on AMPA and NMDA receptors. Proc Natl Acad Sci U S A 98:12772-12777. CrossRef Medline

Chen L, Bohanick JD, Nishihara M, Seamans JK, Yang CR (2007) Dopamine D1/5 receptor-mediated long-term potentiation of intrinsic excitability in rat prefrontal cortical neurons: $\mathrm{Ca}^{2+}$-dependent intracellular signaling. J Neurophysiol 97:2448-2464. CrossRef Medline

Clopath C, Ziegler L, Vasilaki E, Büsing L, Gerstner W (2008) Tagtriggerconsolidation: a model of early and late long-term-potentiation and depression. PLoS Comput Biol 4:e1000248. CrossRef Medline

Cohen JD, Braver TS, Brown JW (2002) Computational perspectives on dopamine function in prefrontal cortex. Curr Opin Neurobiol 12:223 229. CrossRef Medline

Cooper LN, Intrator N, Blais BS, Shouval HZ (2004) Theory of cortical plasticity. Singapore: World Scientific.

Coppa-Hopman R, Galle J, Pimkine D (2009) D1 receptor antagonistinduced long-term depression in the medial prefrontal cortex of rat, in vivo: an animal model of psychiatric hypofrontality. J Psychopharmacol 23:672-685. CrossRef Medline

Dayan P, Abbott LF (2001) Theoretical neuroscience: computational and mathematical modeling of neural systems. Cambridge, MA: Massachusetts Institute of Technology.

DeSteno DA, Schmauss C (2008) Induction of early growth response gene 2 expression in the forebrain of mice performing an attention-set-shifting task. Neuroscience 152:417-428. CrossRef Medline

Destexhe A, Mainen ZF, Sejnowski TJ (1994) An efficient method for computing synaptic conductances based on a kinetic model of receptor binding. Neural Comput 6:14-18. CrossRef

Durstewitz D, Seamans JK, Sejnowski TJ (2000a) Dopamine-mediated stabilization of delay-period activity in a network model of prefrontal cortex. J Neurophysiol 83:1733-1750. Medline

Durstewitz D, Seamans JK, Sejnowski TJ (2000b) Neurocomputational 
models of working memory. Nat Neurosci 3:1184-1191. CrossRef Medline

Floresco SB, Magyar O (2006) Mesocortical dopamine modulation of executive functions: beyond working memory. Psychopharmacology 188 : 567-585. CrossRef Medline

Floresco SB, West AR, Ash B, Moore H, Grace AA (2003) Afferent modulation of dopamine neuron firing differentially regulates tonic and phasic dopamine transmission. Nat Neurosci 6:968-973. CrossRef Medline

Floresco SB, Magyar O, Ghods-Sharifi S, Vexelman C, Tse MT (2006) Multiple dopamine receptor subtypes in the medial prefrontal cortex of the rat regulate set-shifting. Neuropsychopharmacology 31:297-309. CrossRef Medline

Fuster JM (1973) Unit activity in prefrontal cortex during delayed- response performance: neuronal correlates of transient memory. J Neurophysiol 36:61-78. Medline

Fuster JM (2008) The prefrontal cortex. London, UK: Academic.

Gamo NJ, Arnsten AF (2011) Molecular modulation of prefrontal cortex: rational development of treatments for psychiatric disorders. Behav Neurosci 125:282-296. CrossRef Medline

Garris PA, Wightman RM (1994) Different kinetics govern dopaminergic transmission in the amygdala, prefrontal cortex, and striatum: an in vivo voltammetric study. J Neurosci 14:442-450. Medline

Gaspar P, Bloch B, Le Moine C (1995) D1 and D2 receptor gene expression in the rat frontal cortex: cellular localization in different classes of efferent neurons. Eur J Neurosci 7:1050-1063. CrossRef Medline

Gee S, Ellwood I, Patel T, Luongo F, Deisseroth K, Sohal VS (2012) Synaptic activity unmasks dopamine $\mathrm{D}_{2}$ receptor modulation of a specific class of layer $\mathrm{V}$ pyramidal neurons in prefrontal cortex. J Neurosci 32:4959-4971. CrossRef Medline

Goldman-Rakic PS (1995) Cellular basis of working memory. Neuron 14: 477-485. CrossRef Medline

Goto Y, Otani S (2007) Prefrontal cortical synaptic plasticity: the roles of dopamine and implication for schizophrenia In: Monoaminergic modulation of cortical excitability (Tseng KY, Atzori M, eds), pp 165-174. New York: Springer.

Goto Y, Yang CR, Otani S (2010) Functional and dysfunctional synaptic plasticity in prefrontal cortex: roles in psychiatric disorders. Biol Psychiatry 67:199-207. CrossRef Medline

Grace AA (1991) Phasic versus tonic dopamine release and the modulation of dopamine system responsivity: a hypothesis for the etiology of schizophrenia. Neuroscience 41:1-24. CrossRef Medline

Gresch PJ, Sved AF, Zigmond MJ, Finlay JM (2002) Stress-induced sensitization of dopamine and norepinephrine efflux in medial prefrontal cortex of the rat. J Neurochem 63:575-583. CrossRef

Grunditz A, Holbro N, Tian L, Zuo Y, Oertner TG (2008) Spine neck plasticity controls postsynaptic calcium signals through electrical compartmentalization. J Neurosci 28:13457-13466. CrossRef Medline

Gulledge AT, Jaffe DB (1998) Dopamine decreases the excitability of layer V pyramidal cells in the rat prefrontal cortex. J Neurosci 18:9139-9151. Medline

Gulledge AT, Stuart GJ (2003) Action potential initiation and propagation in layer 5 pyramidal neurons of the rat prefrontal cortex: absence of dopamine modulation. J Neurosci 23:11363-11372. Medline

Gurden H, Tassin JP, Jay TM (1999) Integrity of the mesocortical dopaminergic system is necessary for complete expression of in vivo hippocampal-prefrontal cortex long-term potentiation. Neuroscience 94: 1019-1027. CrossRef Medline

Hernandez L, Hoebel BG (1990) Feeding can enhance dopamine turnover in the prefrontal cortex. Brain Res Bull 25:975-979. CrossRef Medline

Herry C, Garcia R (2002) Prefrontal cortex long-term potentiation, but not long term depression, is associated with the maintenance of extinction of learned fear in mice. J Neurosci 22:577-583. Medline

Hines ML, Davison AP, Muller E (2009) NEURON and Python. Front Neuroinform 3:1. CrossRef Medline

Hirsch JC, Crepel F (1990) Use-dependent changes in synaptic efficacy in rat prefrontal neurons in vitro. J Physiol 427:31-49. Medline

Huang YY, Simpson E, Kellendonk C, Kandel ER (2004) Genetic evidence for the bidirectional modulation of synaptic plasticity in the prefrontal cortex by D1 receptors. Proc Natl Acad Sci U S A 101:3236-3241. CrossRef Medline

Jahr CE, Stevens CF (1990) Voltage dependence of NMDA-activated pre- dicted by single-channel kinetics macroscopic conductances. Nature 10:3178-3182.

Jahr CE, Stevens CF (1993) Calcium permeability of the $N$-methyl-Daspartate receptor channel in hippocampal neurons in culture. Proc Natl Acad Sci U S A 90:11573-11577. CrossRef Medline

Jay TM (2003) Dopamine: a potential substrate for synaptic plasticity and memory mechanisms. Prog Neurobiol 69:375-390. CrossRef Medline

Jay TM, Gurden H, Yamaguchi T (1998) Rapid increase in PKA activity during long-term potentiation in the hippocampal afferent fibre system to the prefrontal cortex in vivo. Eur J Neurosci 10:3302-3306. CrossRef Medline

Jung MW, Baeg EH, Kim MJ, Kim YB, Kim JJ (2008) Plasticity and memory in the prefrontal cortex. Rev Neurosci 19:29-46. Medline

Kolomiets B, Marzo A, Caboche J, Vanhoutte P, Otani S (2009) Background dopamine concentration dependently facilitates long-term potentiation in rat prefrontal cortex through postsynaptic activation of extracellular signalregulated kinases. Cereb Cortex 19:2708-2718. CrossRef Medline

Kosobud AE, Harris GC, Chapin JK (1994) Behavioral associations of neuronal activity in the ventral tegmental area of the rat. J Neurosci 14:71177129. Medline

Larkum ME, Nevian T, Sandler M, Polsky A, Schiller J (2009) Synaptic integration in tuft dendrites of layer 5 pyramidal neurons: a new unifying principle. Science 325:756-760. CrossRef Medline

Laroche S, Jay TM, Thierry AM (1990) Long-term potentiation in the prefrontal cortex following stimulation of the hippocampal CAl/subicular region. Neurosci Lett 114:184-190. CrossRef Medline

Lavin A, Nogueira L, Lapish CC, Wightman RM, Phillips PE, Seamans JK (2005) Mesocortical dopamine neurons operate in distinct temporal domains using multimodal signaling. J Neurosci 25:5013-5023. CrossRef Medline

Law-Tho D, Hirsch JC, Crepel F (1994) Dopamine modulation of synaptic transmission in rat prefrontal cortex: an in vitro electrophysiological study. Neurosci Res 21:151-160. CrossRef Medline

Law-Tho D, Desce JM, Crepel F (1995) Dopamine favours the emergence of long-term depression versus long-term potentiation in slices of rat prefrontal cortex. Neurosci Lett 188:125-128. CrossRef Medline

Lee SP, So CH, Rashid AJ, Varghese G, Cheng R, Lança AJ, O’Dowd BF, George SR (2004) Dopamine D1 and D2 receptor co-activation generates a novel phospholipase C-mediated calcium signal. J Biol Chem 279: 35671-35678. CrossRef Medline

Li YC, Xi D, Roman J, Huang YQ, Gao WJ (2009) Activation of glycogen synthase kinase- $3 \beta$ is required for hyperdopamine and $D_{2}$ receptor- mediated inhibition of synaptic NMDA receptor function in the rat prefrontal cortex. J Neurosci 29:15551-15563. CrossRef Medline

Lindskog M, Kim M, Wikström MA, Blackwell KT, Kotaleski JH (2006) Transient calcium and dopamine increase PKA activity and DARPP-32 phosphorylation. PLoS Comput Biol 2:e119. CrossRef Medline

Lisman JE (1985) A mechanism for memory storage insensitive to molecular turnover: a bistable autophosphorylating kinase. Proc Natl Acad Sci U S A 82:3055-3057. CrossRef Medline

Loh M, Rolls ET, Deco G (2007) A dynamical systems hypothesis of schizophrenia. PLoS Comput Biol 3:e228. CrossRef Medline

Malenka RC, Bear MF (2004) LTP and LTD: an embarrassment of riches. Neuron 44:5-21. CrossRef Medline

Matsuda Y, Marzo A, Otani S (2006) The presence of background dopamine signal converts long-term synaptic depression to potentiation in rat prefrontal cortex. J Neurosci 26:4803-4810. CrossRef Medline

Memo M, Lovenberg W, Hanbauer I (1982) Agonist-induced subsensitivity of adenylate cyclase coupled with a dopamine receptor in slices from rat corpus striatum. Proc Natl Acad Sci U S A 79:4456-4460. CrossRef Medline

Miller EK, Cohen JD (2001) An integrative theory of prefrontal cortex function. Annu Rev Neurosci 24:167-202. CrossRef Medline

Missale C, Nash SR, Robinson SW, Jaber M, Caron MG (1998) Dopamine receptors: from structure to function. Physiol Rev 78:189-225. Medline

Morrow BA, Redmond AJ, Roth RH, Elsworth JD (2000) The predator odor, TMT, displays a unique, stress-like pattern of dopaminergic and endocrinological activation in the rat. Brain Res 864:146-151. CrossRef Medline

Morrow B, Elsworth J, Rasmusson A, Roth R (1999) The role of mesoprefrontal dopamine neurons in the acquisition and expression of conditioned fear in the rat. Neuroscience 92:553-564. CrossRef 
Mueller D, Bravo-Rivera C, Quirk GJ (2010) Infralimbic d2 receptors are necessary for fear extinction and extinction-related tone responses. Biol Psychiatry 68:1055-1060. CrossRef Medline

Nakano T, Doi T, Yoshimoto J, Doya K (2010) A kinetic model of dopamine- and calcium-dependent striatal synaptic plasticity. PLoS Comput Biol 6:e1000670. CrossRef Medline

Negyessy L, Goldman-Rakic PS (2005) Subcellular localization of the dopamine $\mathrm{D} 2$ receptor and coexistence with the calcium-binding protein neuronal calcium sensor-1 in the primate prefrontal cortex. J Comp Neurol 488:464-475. CrossRef Medline

O'Connor DH, Wittenberg GM, Wang SS (2005) Graded bidirectional synaptic plasticity is composed of switch-like unitary events. Proc Natl Acad Sci U S A 102:9679-9684. CrossRef Medline

Otani S (2002) Memory trace in prefrontal cortex: theory for the cognitive switch. Biol Rev 77:563-577. CrossRef Medline

Otani S, Blond O, Desce JM, Crepel F (1998) Dopamine facilitates longterm depression of glutamatergic transmission in rat prefrontal cortex. Neuroscience 85:669-676. CrossRef Medline

Otani S, Auclair N, Desce JM, Roisin MP, Crépel F (1999) Dopamine receptors and groups and mGluRs cooperate for long-term depression induction in rat prefrontal cortex through converging postsynaptic activation of kinases. J Neurosci 19:9788-9802. Medline

Otani S, Daniel H, Roisin MP, Crepel F (2003) Dopaminergic modulation of longterm synaptic plasticity in rat prefrontal neurons. Cereb Cortex 13:1251-1256. CrossRef Medline

Pawlak V, Kerr JN (2008) Dopamine receptor activation is required for corticostriatal spike-timing-dependent plasticity. J Neurosci 28:2435-2446. CrossRef Medline

Pezze MA, Feldon J (2004) Mesolimbic dopaminergic pathways in fear conditioning. Prog Neurobiol 74:301-320. CrossRef Medline

Phillips AG, Ahn S, Floresco SB (2004) Magnitude of dopamine release in medial prefrontal cortex predicts accuracy of memory on a delayed response task. J Neurosci 24:547-553. CrossRef Medline

Reynolds JN, Wickens JR (2002) Dopamine-dependent plasticity of corticostriatal synapses. Neural Netw 15:507-521. CrossRef Medline

Rolls ET, Loh M, Deco G, Winterer G (2008) Computational models of schizophrenia and dopamine modulation in the prefrontal cortex Nat Rev Neurosci 9:696-709. CrossRef

Rougier NP, Noelle DC, Braver TS, Cohen JD, O’Reilly RC (2005) Prefrontal cortex and flexible cognitive control: rules without symbols. Proc Natl Acad Sci U S A 102:7338-7343. CrossRef Medline

Sajikumar S, Frey JU (2004) Late-associativity, synaptic tagging, and the role of dopamine during LTP and LTD. Neurobiol Learn Mem 82:12-25. CrossRef Medline

Santana N, Mengod G, Artigas F (2009) Quantitative analysis of the expression of dopamine D1 and D2 receptors in pyramidal and GABAergic neurons of the rat prefrontal cortex. Cereb Cortex 19:849-860. CrossRef Medline

Schultz W, Dayan P, Montague PR (1997) A neural substrate of prediction and reward. Science 275:1593-1599. CrossRef Medline

Seamans JK, Yang CR (2004) The principal features and mechanisms of dopamine modulation in the prefrontal cortex. Prog Neurobiol [Erratum (2004) 74:321] 74:1-58. CrossRef Medline

Seamans JK, Floresco SB, Phillips AG (1998) D1 receptor modulation of hippocampal-prefrontal cortical circuits integrating spatial memory with executive functions in the rat. J Neurosci 18:1613-1621. Medline

Setlow B, McGaugh JL (2000) D2 dopamine receptor blockade immediately post-training enhances retention in hidden and visible platform versions of the water maze. Learn Mem 7:187-191. CrossRef Medline

Sheynikhovich D, Otani S, Arleo A (2011) The role of tonic and phasic dopamine for long-term synaptic plasticity in the prefrontal cortex: a computational model. J Physiol Paris 105:45-52. CrossRef Medline

Shouval HZ, Bear MF, Cooper LN (2002) A unified model of NMDA receptor-dependent bidirectional synaptic plasticity. Proc Natl Acad Sci U S A 99:10831-10836. CrossRef Medline

Sirota A, Montgomery S, Fujisawa S, Isomura Y, Zugaro M, Buzsáki G (2008)
Entrainment of neocortical neurons and gamma oscillations by the hippocampal theta rhythm. Neuron 60:683-697. CrossRef Medline

St Onge JR, Abhari H, Floresco SB (2011) Dissociable contributions by prefrontal $\mathrm{D}_{1}$ and $\mathrm{D}_{2}$ receptors to risk-based decision making. J Neurosci 31:8625-8633. CrossRef Medline

Sun X, Zhao Y, Wolf ME (2005) Dopamine receptor stimulation modulates AMPA receptor synaptic insertion in prefrontal cortex neurons. J Neurosci 25:7342-7351. CrossRef Medline

Thivierge JP, Rivest F, Monchi O (2007) Spiking neurons, dopamine, and plasticity: timing is everything, but concentration also matters. Synapse 61:375-390. CrossRef Medline

Thomas GM, Huganir RL (2004) MAPK cascade signalling and synaptic plasticity. Nat Rev Neurosci 5:173-183. CrossRef Medline

Thurley K, Senn W, Lüscher HR (2008) Dopamine increases the gain of the input-output response of rat prefrontal pyramidal neurons. J Neurophysiol 99:2985-2997. CrossRef Medline

Toyoizumi T, Pfister JP, Aihara K, Gerstner W (2007) Optimality model of unsupervised spike-timing-dependent plasticity: synaptic memory and weight distribution. Neural Comput 19:639-671. CrossRef Medline

Trantham-Davidson H, Neely LC, Lavin A, Seamans JK (2004) Mechanisms underlying differential $D_{1}$ versus $D_{2}$ dopamine receptor regulation of inhibition in prefrontal cortex. J Neurosci 24:10652-10659. CrossRef Medline

Tritsch NX, Sabatini BL (2012) Dopaminergic modulation of synaptic transmission in cortex and striatum. Neuron 76:33-50. CrossRef Medline

Tseng KY, O'Donnell P (2004) Dopamine-glutamate interactions controlling prefrontal cortical pyramidal cell excitability involve multiple signaling mechanisms. J Neurosci 24:5131-5139. CrossRef Medline

Turrigiano GG (2008) The self-tuning neuron: synaptic scaling of excitatory synapses. Cell 135:422-435. CrossRef Medline

Turrigiano GG, Nelson SB (2004) Homeostatic plasticity in the developing nervous system. Nat Rev Neurosci 5:97-107. CrossRef Medline

Vincent SL, Khan Y, Benes FM (1993) Cellular distribution prefrontal cortex of dopamine $\mathrm{D}_{1}$ and $\mathrm{D}_{2}$ receptors in rat medial prefrontal cortex. J Neurosci 13:2551-2564. Medline

Vincent SL, Khan Y, Benes FM (1995) Cellular colocalization of dopamine D1 and D2 receptors in rat medial prefrontal cortex. Synapse 19:112-120. CrossRef Medline

Wang X, Zhong P, Gu Z, Yan Z (2003) Regulation of NMDA receptors by dopamine $\mathrm{D}_{4}$ signaling in prefrontal cortex. J Neurosci 23:9852-9861. Medline

Xu TX, Yao WD (2010) D1 and D2 dopamine receptors in separate circuits cooperate to drive associative long-term potentiation in the prefrontal cortex. Proc Natl Acad Sci U S A 107:16366-16371. CrossRef Medline

Xu TX, Sotnikova TD, Liang C, Zhang J, Jung JU, Spealman RD, Gainetdinov RR, Yao WD (2009) Hyperdopaminergic tone erodes prefrontal longterm potential via a $\mathrm{D}_{2}$ receptor-operated protein phosphatase gate. J Neurosci 29:14086-14099. CrossRef Medline

Yamada WM, Koch C, Adams PR (1999) Multiple channels and calcium dynamics. In: Methods in neuronal modeling: from ions to networks, Ed 2 (Koch C, Segev I, eds), pp 137-170. Cambridge, MA: Massachusetts Institute of Technology.

Yang CR, Seamans JK, Gorelova N (1999) Developing a neuronal model for the pathophysiology of schizophrenia based on the nature of electrophysiological actions of dopamine in the prefrontal cortex. Neuropsychopharmacology 21:161-194. CrossRef Medline

Yeung LC, Shouval HZ, Blais BS, Cooper LN (2004) Synaptic homeostasis and input selectivity follow from a calcium-dependent plasticity model. Proc Natl Acad Sci U S A 101:14943-14948. CrossRef Medline

Zhang ZW, Burke MW, Calakos N, Beaulieu JM, Vaucher E (2010) Confocal analysis of cholinergic and dopaminergic inputs onto pyramidal cells in the prefrontal cortex of rodents. Front Neuroanat 4:21. CrossRef Medline

Zheng P, Zhang XX, Bunney BS, Shi WX (1999) Opposite modulation of cortical $N$-methyl-D-aspartate receptor-mediated responses by low and high concentrations of dopamine. Neuroscience 91:527-535. CrossRef Medline 